\title{
Heterogeneous Premiums for Homogeneous Risks? Asset Liability Management under Default Probability and Price-Demand Functions
}

\section{Florian Klein \& Hato Schmeiser}

To cite this article: Florian Klein \& Hato Schmeiser (2019) Heterogeneous Premiums for Homogeneous Risks? Asset Liability Management under Default Probability and Price-Demand Functions, North American Actuarial Journal, 23:2, 276-297, DOI: 10.1080/10920277.2018.1538805

To link to this article: https://doi.org/10.1080/10920277.2018.1538805

Published online: 11 Mar 2019.

Submit your article to this journal $₫$

Џll Article views: 165

Q View related articles ¿

View Crossmark data

Citing articles: 1 View citing articles \ulcorner 


\title{
Heterogeneous Premiums for Homogeneous Risks? Asset Liability Management under Default Probability and Price-Demand Functions
}

\author{
Florian Klein and Hato Schmeiser \\ Institute of Insurance Economics, University of St. Gallen, St. Gallen, Switzerland
}

\begin{abstract}
We consider an asset liability model under an internal solvency constraint that includes default probability as well as pricedemand functions and combine insights from empirical and theoretical research. Furthermore, as a result of policyholders' heterogeneous willingness to pay, we introduce heterogeneous premiums to maximize the insurer's overall net present value and compare the results with an optimal homogeneous premium. To determine a reservation price for the insurer, we use the MargrabeFischer option-pricing formula. Our numerical examples document that heterogeneous premiums for homogeneous risks improve the net present value when correct expectations underlie and are vulnerable against a cost shift but do not per se induce a decrease in the net present value. Moreover, we recognize that the optimal price setting under overall net present value maximization varies from the underwriting net present value maximization on the individual risk level. Hence, in practice, an overall asset liability management perspective should be in focus to reach the best results from the company's point of view.
\end{abstract}

\section{INTRODUCTION}

In times of low interest rates and possible "bubbles" in various asset classes, financial institutions face the challenge of generating appropriate returns from their invested capital. In general, funds have more risky investments on the strategic map (see, e.g., Di Maggio and Kacperczyk 2017; Choi and Kronlund 2018), whereas an insurer's investment behavior is rather restricted by regulatory requirements, such as the Solvency II Directive (see, e.g., Braun et al. 2014). However, improving an insurer's return on capital is not determined only by the investment strategy. Underwriting profit generation, which we describe as policyholders' premiums minus costs, also represents an integral component for improved profitability. In addition, to improve the insurer's performance or to be in line with its risk appetite, the insurance company could also purchase a reinsurance contract to achieve several objectives. While various studies analyze optimal investment strategies (see, e.g., Braun et al. 2014, 2017; Eckert and Gatzert 2018) and optimal reinsurance designs (see, e.g., Tan and Weng 2014; Cheung et al. 2017), we set underwriting profit generation as the focus. In contrast to, e.g., Braun et al. $(2014,2017)$, we do not assume that the pool of policyholders is given, and hence it is not a decision variable for the insurer. The environment in which insurers operate is dynamic and thus changes time-dependently. Therefore, we recognize the demand for insurance as well as policyholders' willingness to pay a premium as important parameters for an insurer's profitability.

Furthermore, we include insights about the inherent existence of default probability and the relation between default probability and willingness to pay a premium in our analysis. Concerning the existence of default probability, previous research clarifies that a nondefault assumption is not adequate as a result of the systemic risk within the financial world. The financial crisis has illustrated that even institutions that are regarded as too-big-to-fail can actually fail (see, e.g., Harrington 2009; Brownlees and Engle 2017). According to the relation between default probability and willingness to pay a premium, Wakker et al. (1997) and Zimmer et al. (2009, 2018) emphasize with their empirical research that even a low default probability (if transparent) substantially reduces the willingness to pay. Based on this research, we derive a relation between default probability and willingness to pay a premium and embed it in our asset liability model. Moreover, we implement a price-demand function. In the context of substandard annuities, Gatzert et al. (2012) use a linear price-demand function. They analyze the optimal price-demand combination in a certain risk class and examine how different subpopulations influence the optimal price-demand combination. In addition, they include a misclassification of the risk class and the effect on the optimal pricedemand combination in their investigation. Einav and Finkelstein (2011) also use a linear price-demand function in their

Address correspondence to Florian Klein, Institute of Insurance Economics, University of St. Gallen, Tannenstrasse 19, CH-9000 St. Gallen, Switzerland. E-mail: florian.klein@unisg.ch 
analysis of adverse selection in the insurance market. In contrast, Zimmer et al. (2018) show that a convex price-demand function underlies their empirical data set. Including both views in our approach, we first assume a linear price-demand function and later introduce the convex price-demand function, which in our case possesses the same reservation price and actuarially fair premium as the linear function.

Derived from the insight that heterogeneous customers have a heterogeneous willingness to pay (see Zimmer et al. 2018), we extend previous research that considers an optimal premium-demand combination (see, e.g., Gatzert et al. 2012) and investigations that focus on reduction of the willingness to pay if default may take place (see, e.g., Schlütter 2014; Eckert and Gatzert 2018). Hence, we introduce heterogeneous premiums and analyze how different premium levels influence the insurer's overall net present value (NPV). Moreover, we show in detail that the optimal demand varies between an isolated premiumcosts consideration (as done, e.g., in Gatzert et al. 2012) and an overall perspective. In addition, we emphasize that heterogeneous premiums exhibit the potential to induce a shift in the mind-set of an insurance enterprise. The insurance enterprise adapts the insurance premium to the willingness to pay and not the policyholder's willingness to pay to the insurance premium (which is only possible downward). We evolve an internal solvency constraint and focus on a scenario under correct expectations as well as a cost shift. In this context, we include uncertainty, which is described as a simple variation in the expected costs from different points in time.

In summary, we develop an asset liability model based on default probability as well as price-demand functions and use heterogeneous premiums to maximize the net present value of the insurer. Net present values are calculated by using the Margrabe-Fischer option-pricing formula. We combine insights from theoretical as well as empirical research, and, as outlined above, we extend previous research in several ways. Our aim is to critically reflect the use of heterogeneous premiums under default probability, price-demand functions, solvency constraint, and further model assumptions. This article is organized as follows. In Section 2, we thematize the relation among default probability, price-demand function, and premium as the basis for our asset liability model in Section 3. The structure of assets and liabilities, heterogeneous premiums, and the constraints are the focus of Section 3. Furthermore, in Section 4 we run a numerical analysis and compare the results under a scenario of correct expectations as well as misjudgment of expected costs. The economic implications of our findings are discussed in Section 5. Section 6 concludes with the main insights.

\section{INFLUENCE OF DEFAULT PROBABILITY AND PRICE-DEMAND FUNCTION ACCORDING TO INSURANCE PREMIUM}

\subsection{Central Assumptions for the Two Stakeholder Groups}

In this article, we strive for a shareholder value (overall net present value) maximization measured by the Margrabe-Fischer option-pricing formula. In this context, we assume that insurance companies have access to a frictionless and complete capital market and can replicate future cash flows. Hence, reservation prices for insurance contracts from the provider perspective are under the Margrabe-Fischer option-pricing formula given by the price of the replication portfolio (risk-neutral valuation technique). We assume that policyholders cannot replicate future cash flows and face a price-demand function. In addition, their willingness to pay for insurance depends on the default risk of the insurer (see, e.g., Wakker et al. 1997; Zimmer et al. 2009, 2018). The willingness to pay on the policyholders' side is, due to risk aversion, typically higher than the risk-neutral price derived by the Margrabe-Fischer option-pricing formula.

\subsection{Default Probability and Insurance Premium}

From the perspective of rational behavior, an increase of 1 percentage point default probability decreases for a given insurance amount the actuarially fair premium by 1 percentage point. However, individuals do not behave completely rationally, even when they intend to be rational. Instead, humans often act under the condition of bounded rationality (see Simon 1957). As a result of restricted abilities, individuals overweight or ignore very unlikely events (see Kahneman and Tversky 1979). From the insurance company perspective, it is not critical when a policyholder ignores (extreme) risk events that lead to a default of the insurance. More precisely, the willingness to pay a certain premium is not reduced by the existence of a potential risk when the policyholder does not recognize the risk (e.g., the potential default of an insurance contract is often not taken into consideration). However, previous research clarifies that if a low default probability is given and the policyholders are aware of such risk, the willingness to pay a premium decreases substantially.

Wakker et al. (1997) analyze the willingness to pay an insurance premium and underlie either a default-free insurance or a 1 percent default probability. The authors demonstrate with a direct survey that the existence of 1 percent default probability 
TABLE 1

Empirical Research about Default Probability and Insurance Premium

\begin{tabular}{|c|c|c|c|}
\hline & Wakker et al. (1997) & Zimmer et al. (2009) & Zimmer et al. (2018) \\
\hline Default probability $(\%)$ & 0,1 & $0,0.3,4.9$ & $0,1,2,3$ \\
\hline Median/mean & Median: & Mean: & Mean: \\
\hline Premium reduction $(\%)$ & higher 20 (1) & $14(0.3), 26(4.9)$ & $25(1), 38.04(2), 50(3)$ \\
\hline Technique & Direct survey & Online questionnaire & Laboratory experiment \\
\hline Participants (no.) & $\begin{array}{c}\text { Students (230), } \\
\text { money managers (75) }\end{array}$ & $\begin{array}{l}\text { No target audience; } \\
\text { invited via e-mail (719) }\end{array}$ & $\begin{array}{l}\text { Students (117), } \\
\text { employee (28), other (36) }\end{array}$ \\
\hline Type of insurance & $\begin{array}{l}\text { Fire insurance, car insurance, } \\
\text { international investment }\end{array}$ & Household insurance & Theft insurance \\
\hline
\end{tabular}

leads to a premium reduction of the median of more than 20 percent to compensate the potential default. Zimmer et al. (2009) generate similar results based on an online questionnaire. For a 0.3 percent default probability, the mean premium decreases by 14 percent related to a default-free insurance. A 4.9 percent default probability leads to a mean reduction of 26 percent. The findings of Zimmer et al. (2018) also illustrate the substantial decrease in policyholders' willingness to pay a premium in the context of probabilistic insurance. ${ }^{1}$ Table 1 summarizes the above-mentioned empirical research.

Based on the analyzed empirical research, the question becomes how the willingness to pay a premium and default risk are related. Derived from the insights of Zimmer et al. (2009), Lorson et al. (2012) formulate a logarithmic regression to describe the relation between default probability $D P_{i j}$ (which describes the default risk) and the premium reduction $\pi_{\text {mean }}^{R}$. More concretely, $D P_{i j}$ is understood as the probability that an insurance contract between insurer $i$ and policyholder $j$ results in a default

$$
\pi_{\text {mean }}^{R}\left(D P_{i j}\right)=0.0419 \ln \left(D P_{i j}\right)+0.3855 \forall D P_{i j}(0,1]
$$

Thus,

$$
\pi_{\text {mean }}\left(D P_{i j}\right)=1-\pi_{\text {mean }}^{R}\left(D P_{i j}\right)=1-\left(0.0419 \ln \left(D P_{i j}\right)+0.3855\right)
$$

is defined as the mean premium $\pi_{\text {mean }}$, which is paid dependent on $D P_{i j}$. Lorson et al. (2012) argue that this type of regression is a good fit for small default probabilities. However, the empirical study of Zimmer et al. (2018) shows that an exponential regression is more suitable to explain the dependency between default probability and mean premium. In the following sections, we use the exponential regression for two reasons. First, the amount of examined default probabilities is higher in Zimmer et al. (2018) than in Zimmer et al. (2009). Second, the interval between the analyzed default probabilities is equal in Zimmer et al. (2018). More precisely, the default probability increases by 1 percentage point per investigated level. In contrast, the examined default probability jumps in Zimmer et al. (2009) among 0, 0.3, or 4.9 percent. This nonlinear default probability development makes it difficult for policyholders to become cognizant of their actual willingness to pay. Our exponential regression is based on the results of the mean premium

$$
\pi_{\text {mean }}\left(D P_{i j}\right)=\exp \left(-23.75 D P_{i j}\right) .
$$

This implies that for a default probability of 0 the premium is equal to 100 percent. However, the assumption of no default probability is not realistic. The recent financial crisis has shown that even organizations and financial products with the highest ratings exhibit an inherent default probability (cf., e.g., Lehman Brothers and collateralized debt obligations [CDOs; see, e.g., Harrington 2009; Brownlees and Engle 2017]). Figure 1 illustrates the logarithmic regression of Lorson et al. (2012) and our exponential regression, which is derived from Zimmer et al. (2018).

\footnotetext{
${ }^{1}$ When a hazard or damage occurs, the probabilistic insurance pays off only with a probability smaller than 1 (see Kahneman and Tversky 1979; Wakker et al. 1997). A probabilistic insurance can be induced by the insurance company itself, which structures the insurance contract in a way that there is a payoff only with a probability lower than 1 or an inherent default probability (e.g., caused by systemic risk) leads to a probabilistic insurance.
} 


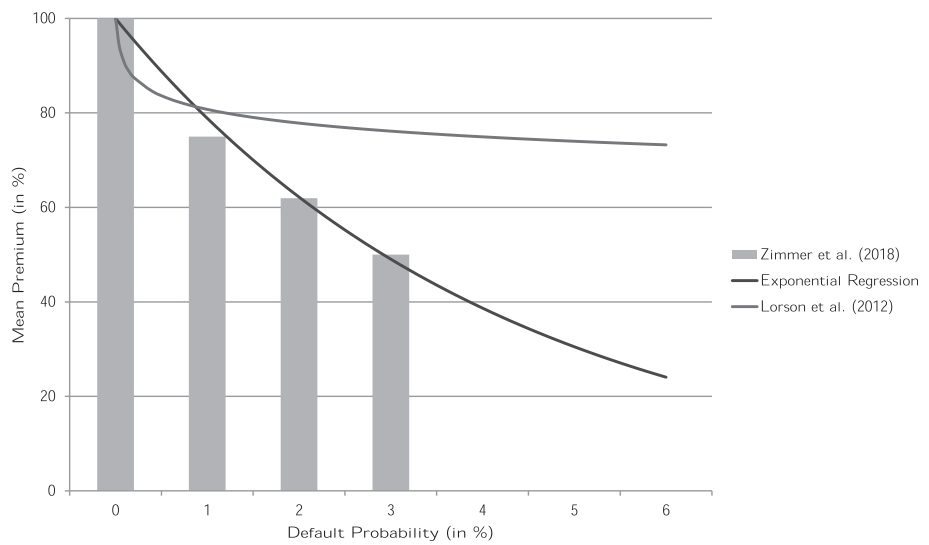

FIGURE 1. Default Probability and Mean Premium.

\subsection{Price-Demand Function and Optimal Insurance Premium on the Underwriting Level}

Initially, we analyze the relation between price-demand function and optimal insurance premium on the underwriting perspective to clarify our basic idea. In this regard, it is important to mention that the results of an underwriting level are typically not optimal from the insurer's perspective, which we will show later. Subsequently we develop a model in which the premium depends on the default probability $D P_{i j}$ as well as a price-demand function PDF.

We consider a price-demand function of insurer $i$ and set $i$ to 1 because we analyze in the next section the asset liability model of one specific insurance company. Including this notation, following Gatzert et al. (2012) and Einav and Finkelstein (2011), first a linear price-demand function is in focus to clarify our approach. Afterward, we extend the model to nonlinearity (see, e.g., Caginalp 2005; Zimmer et al. 2018). The price-demand function exhibits the following form:

$$
\pi^{P D F}\left(\sum_{j=1}^{n} x_{1 j}\right)=\pi_{r}-\theta \sum_{j=1}^{n} x_{1 j},
$$

where $\pi^{P D F}\left(\sum_{j=1}^{k} x_{1 j}\right)=0$ and $k \geq n$. Furthermore, $\pi_{r}$ is the reservation price, ${ }^{2} \sum_{j=1}^{n} x_{1 j}$ is the demand, where $n$ represents the number of demanders, and $\theta$ determines the negative slope of the graph, which remains constant. The expected cost function

$$
E\left(c\left(\sum_{j=1}^{n} x_{1 j}\right)\right)=\pi_{a}
$$

is not influenced by the number of insurance contracts and describes which premium is needed to compensate the expected costs of insurance (see also Gatzert et al. 2012). Hence, we consider risks that are homogeneous with respect to their distribution function. In the first step, we maximize the expected underwriting profit $E\left(P_{r}\right)$, which can be generated through the premium-cost relation. Derived from the current economic situation, we suppose a risk-free interest rate of 0 . With $x^{N}:=\sum_{j=1}^{n} x_{1 j}$, optimal demand $x^{o p t}$ and optimal premium $\pi^{\text {opt }}$ can be determined through

$$
\frac{d E\left(P_{r}\left(x^{N}\right)\right)}{d x^{N}}=\frac{d\left(\pi^{P D F}\left(x^{N}\right) x^{N}\right)}{d x^{N}}-\frac{d\left(E\left(c\left(x^{N}\right)\right) x^{N}\right)}{d x^{N}} \stackrel{!}{=} 0 .
$$

Thus, the optimal point isv

$$
x^{o p t}=\frac{\pi_{r}-\pi_{a}}{2 \theta} ; \quad \pi^{o p t}=\pi_{r}-\theta \frac{\pi_{r}-\pi_{a}}{2 \theta}=\frac{\pi_{r}+\pi_{a}}{2},
$$

and this is a maximum for $\theta>0$ because $\frac{d^{2} E\left(P_{r}\left(x^{N}\right)\right)}{d x^{2}}<0$. However, in the linear case, the optimal premium-demand combination only enables realizing 50 percent of the potential expected underwriting profit $\int_{0}^{x^{S}}\left(\pi^{P D F}\left(x^{N}\right)-E\left(c\left(x^{N}\right)\right)\right) d x^{N}$, where $x^{S}$ is the point of intersection between $\pi^{P D F}\left(x^{N}\right)$ and $E\left(c\left(x^{N}\right)\right)$. This insight is independent of $\theta$ and holds for $\pi_{r}>\pi_{a}$. Theoretically, it would be optimal to adapt the premium continuously to the demand quantity to reach the whole integral between $\pi^{P D F}\left(x^{N}\right)$

\footnotetext{
${ }^{2}$ We denote the reservation price $\pi_{r}$ as the point at which the potential customers start to buy the insurance contract (see also Gatzert et al. 2012).
} 


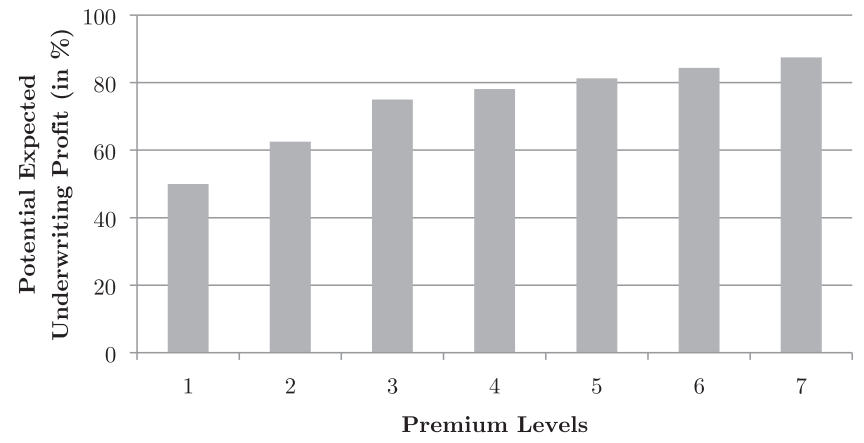

FIGURE 2. Potential Expected Underwriting Profit and Premium Levels.

and $E\left(c\left(x^{N}\right)\right) .{ }^{3}$ However, a continuous premium adaptation is not realistic in practice. ${ }^{4}$ Nevertheless, it is possible to increase the total expected underwriting profit as a consequence of using heterogeneous premiums. ${ }^{5}$ For instance, when an insurer chooses the right two additional premiums given the optimal homogeneous premium, the total expected underwriting profit increases by 50 percent. The two additional premiums are determined as

$$
\pi^{h i g h}=\frac{\pi_{r}+\frac{\pi_{r}+\pi_{a}}{2}}{2} ; \quad \pi^{\text {low }}=\frac{\frac{\pi_{r}+\pi_{a}}{2}+\pi_{a}}{2} .
$$

Here $\pi^{\text {high }}$ maximizes the additional expected underwriting profit of the integral $\int_{0}^{x p t}\left(\pi^{P D F}\left(x^{N}\right)-\pi^{o p t}\right) d x^{N}$, where $\pi^{\text {opt }}$ builds the lower bound since this premium level is already realized. Moreover, the additional expected underwriting profit of $\int_{x^{o p t}}^{x^{S}}\left(\pi^{P D F}\left(x^{N}\right)-E\left(c\left(x^{N}\right)\right)\right) d x^{N}$ is maximized by $\pi^{\text {low }}$. As a result of the linearity, the additional expected underwriting profit that results from $\pi^{\text {high }}$ and $\pi^{\text {low }}$ is equal. The following formula describes the dependency between expected underwriting profit and heterogeneous premiums that maximize $E\left(P_{r}^{\text {total }}\right)$ when each additional premium level builds on the previous optimal premiums: ${ }^{6}$

$$
E\left(P_{r}^{\text {total }}\right)=E\left(P_{r}^{o p t}\right)+\sum_{l=1}^{m} \beta_{l}\left(\frac{1}{4}\right)^{l} E\left(P_{r}^{o p t}\right)
$$

where $\beta_{l}$ denotes the number of areas with equal size and can exhibit values from 0 to $2^{l} ; \beta_{l}$ increases until $2^{l}$ before $l$ increases by 1 . Heterogeneous premium levels are $\pi^{l e v e l}=1+\sum_{l=1}^{m} \beta_{l}$. Figure 2 shows how much of the potential expected underwriting profit can be generated by introducing different premium levels.

The idea is to absorb the willingness to pay a certain premium. From the perspective of perfect competition, such an increase in the potential profit is impossible. However, imperfect information restricts the degree of competition in the insurance market (see also Rothschild and Stiglitz 1976). Information asynchronicity (asymmetry over time) can result from either the market side (e.g., market access or nontransparent markets) or the insurer-customer relationship (e.g., various risk attitudes of individuals ${ }^{7}$ (see also Ellsberg 1961; Tversky and Wakker 1995), adverse selection (see Rothschild and Stiglitz 1997), or moral hazard (see Holmström 1979)) and leads to a heterogeneous willingness to pay. For instance, Zimmer et al. (2018) demonstrate that a heterogeneous willingness to pay a premium is omnipresent and thus should be implemented from the insurer's point of view to maximize profits.

\footnotetext{
${ }^{3}$ Such a process is also known as price discrimination (see, e.g., Pindyck and Rubinfeld 2013).

${ }^{4}$ Continuous premium adaptation typically reduces the acceptance of policyholders, induces reputational risks and additional transaction costs, and may not be achievable because of regulatory requirements.

${ }^{5}$ The pertinent literature considers heterogeneous consumers and beliefs in the context of asset pricing and strives for equilibrium models (see, e.g., Constantinides and Duffie 1996; Brav et al. 2002; Basak 2005). Moreover, Crocker and Snow (2013) examine risk classification with heterogeneous agents.

${ }^{6}$ When heterogeneous premiums are set independently of the optimal homogeneous premium, it is partly possible to reach higher expected underwriting profits. On the other hand, a deviation from the optimal homogeneous premium implies the risk that the expected underwriting profit decreases if the intended number of premium levels cannot be reached induced by, for instance, regulatory requirements. We examine in the following a stepwise optimal price setting. Hence, an additional premium level builds on already set premiums.

${ }^{7}$ For instance, the risk preference of individuals varies with the underlying degree and source of uncertainty (see also Ellsberg 1961; Tversky and Wakker 1995).
} 


\subsection{Interaction among Default Probability, Price-Demand Function, and Insurance Pricing}

After we analyze the relation between default probability and premium as well as price-demand function and optimal premium, in the next step we combine both examinations. With $D P^{A}:=D P_{1 j}=\ldots=D P_{1 n}, \pi_{m e a n}^{P D F}$ is described as

$$
\pi_{\text {mean }}^{P D F}\left(D P^{A}, x^{N}\right)=\left(\pi_{r}-\theta x^{N}\right) \exp \left(-23.75 D P^{A}\right),
$$

where $\pi_{\text {mean }}^{P D F}$ is strictly monotonic decreasing for an increasing $D P^{A}$. Thus, the optimal point is

$$
\begin{aligned}
x_{*}^{o p t} & =\frac{\exp \left(-23.75 D P^{A}\right) \pi_{r}-\pi_{a}\left(D P^{A}\right)}{2 \theta \exp \left(-23.75 D P^{A}\right)}, \\
\pi_{*}^{o p t} & =\frac{\exp \left(-23.75 D P^{A}\right) \pi_{r}+\pi_{a}\left(D P^{A}\right)}{2} .
\end{aligned}
$$

The optimal demand with default probability $x_{*}^{\text {opt }}$ is smaller than without default probability $x^{\text {opt }}$ since it holds that

$$
\begin{aligned}
& x_{*}^{o p t}<x^{o p t}, \\
& \frac{\exp \left(-23.75 D P^{A}\right) \pi_{r}-\pi_{a}\left(D P^{A}\right)}{2 \theta \exp \left(-23.75 D P^{A}\right)}<\frac{\pi_{r}-\pi_{a}}{2 \theta}, \\
& 1<\frac{1-D P^{A}}{\exp \left(-23.75 D P^{A}\right)} .
\end{aligned}
$$

The exponential function overcompensates the linear function as long as the default probability does not converge to 1 . If the default probability converges to 1 , the linear function can overcompensate the exponential function. However, because of solvency requirements, we consider low default probabilities, and hence it holds that $x_{*}^{o p t}<x^{o p t}$. Furthermore,

$$
\begin{gathered}
\pi_{*}^{o p t}<\pi^{o p t}, \\
\frac{\exp \left(-23.75 D P^{A}\right) \pi_{r}+\pi_{a}\left(D P^{A}\right)}{2}<\frac{\pi_{r}+\pi_{a}}{2},
\end{gathered}
$$

as $\pi_{a}\left(D P^{A}\right)<\pi_{a}$ and $\exp \left(-23.75 D P^{A}\right)<1$. Therefore, it is important to consider the default probability in regard to the optimal premium. Moreover, the price-demand function and the default probability are necessary to understand policyholders' behavior adequately. Our previous analysis clarifies that the premium is not a constant factor, which is ex ante given (as it is considered, e.g., in Kahane and Nye 1975). In the next section, we will implement the insights according to the dependency among the premium, default probability, and price-demand function in an asset liability framework to emphasize the necessity in the context of risk and insurance management. Before we define the asset liability framework, we provide additional insights induced by a general consideration.

We compare in the next step a scenario under default and nondefault, where $x^{S}$ remains constant with a varying default probability. Moreover, we analyze how the reservation price under default $\pi_{r}\left(D P^{A}\right)$ has to change to reach equality between the potential expected underwriting profit of the nondefault and the default case. In formal terms, we have

$$
\begin{aligned}
\int_{0}^{x^{S}}\left(\pi^{P D F}\left(x^{N}\right)-E\left(c\left(x^{N}\right)\right)\right) d x^{N} & =\int_{0}^{x^{S}}\left(\pi^{P D F}\left(x^{N}, D P^{A}\right)-E\left(c\left(x^{N}, D P^{A}\right)\right)\right) d x^{N}, \\
\int_{0}^{x^{S}}\left(\pi_{r}-\theta x^{N}-E\left(c\left(x^{N}\right)\right)\right) d x^{N} & =\int_{0}^{x^{S}}\left(\pi_{r}\left(D P^{A}\right)-\theta\left(D P^{A}\right) x^{N}-\left(1-D P^{A}\right) E\left(c\left(x^{N}\right)\right)\right) d x^{N}, \\
\pi_{r} x^{S}-\frac{1}{2} \theta\left(x^{S}\right)^{2}-E\left(c\left(x^{S}\right)\right)_{x^{S}} & =\pi_{r}\left(D P^{A}\right)_{x^{S}}-\frac{1}{2} \theta\left(D P^{A}\right)\left(x^{S}\right)^{2}-\left(1-D P^{A}\right) E\left(c\left(x^{S}\right)\right)_{x^{S}}, \\
\pi_{r}\left(D P^{A}\right) & =\pi_{r}+\left(\theta\left(D P^{A}\right)-\theta\right) \frac{1}{2} x^{S}-D P^{A} E\left(c\left(x^{S}\right)\right) .
\end{aligned}
$$


Hence, the reservation price under default, which leads to the same potential expected underwriting profit as under nondefault, is affected by the reservation price under nondefault, the change of the slope, as well as the reduction of the expected costs.

\section{ASSET LIABILITY MODEL FRAMEWORK}

For our analysis, we develop a one-period model for nonlife insurance companies that includes assets $A_{t}\left(D P^{A}, x^{N}\right)$ and liabilities $L_{t}\left(D P^{A}, x^{N}\right)$ to derive the equity capital $E C_{t}\left(D P^{A}, x^{N}\right) .{ }^{8}$ Including the fact that our model is generated for one period, the following relation results when taking the limited liabilities of shareholders into account:

$$
E C_{1}\left(D P^{A}, x^{N}\right)=\max \left(A_{1}\left(D P^{A}, x^{N}\right)-L_{1}\left(D P^{A}, x^{N}\right), 0\right) .
$$

$A_{1}\left(D P^{A}, x^{N}\right)$ is the stochastic value of assets at time 1 , where it stems from the product of assets at time 0 and the value change between $t=0$ and $t=1$. Given a complete and frictionless capital market, we have with

$$
P V\left(A_{1}\left(D P^{A}, x^{N}\right)\right)=A_{0}\left(D P^{A}, x^{N}\right) ; \quad P V\left(L_{1}\left(D P^{A}, x^{N}\right)\right)=L_{0}\left(D P^{A}, x^{N}\right)
$$

a market equilibrium, where $P V\left(L_{1}\left(D P^{A}, x^{N}\right)\right)$ stands for the present value of the liabilities (stochastic in $\left.t=1\right)$. The initial capital $A_{0}\left(D P^{A}, x^{N}\right)$ is subdivided in the equity capital $E C_{0}$ as well as the premium $\pi_{\text {mean }}^{P D F}\left(D P^{A}, x^{N}\right) x^{N}$ at $t=0$ :

$$
A_{0}\left(D P^{A}, x^{N}\right)=E C_{0}+\pi_{\text {mean }}^{P D F}\left(D P^{A}, x^{N}\right) x^{N} .
$$

This equation holds if one premium level exists. We will later implement heterogeneous premiums. Our model extends the ideas of Eckert and Gatzert (2018) and assumes that the willingness to pay is also affected by a price-demand function. In general, our premium levels are higher than the risk-neutral equilibrium premium as a result of the assumed price-demand function. The expected liabilities $E\left(L_{1}\left(D P^{A}, x^{N}\right)\right)$ consist of the expected indemnity payments $E\left(C_{1}\left(D P^{A}, x^{N}\right)\right)$ at $t=1$ :

$$
E\left(L_{1}\left(D P^{A}, x^{N}\right)\right)=E\left(C_{1}\left(D P^{A}, x^{N}\right)\right)=E\left(c_{1}\left(D P^{A}\right)\right) x^{N},
$$

where $C_{1}\left(D P^{A}, x^{N}\right)$ denotes the indemnity payments of all homogeneous risks. Furthermore, we suppose that $E\left(C_{1}\left(D P^{A}, x^{N}\right)\right)$ is strictly monotonic decreasing in $D P^{A}$. More precisely, with an underlying probabilistic insurance, the probability is inherent that the insurance does not pay the claims of the policyholder, and hence $E\left(C_{1}\left(D P^{A}, x^{N}\right)\right)$ is reduced. According to the pricedemand function, we described the expected cost function $E\left(c\left(x^{N}\right)\right)$ as a constant factor in Section 2. Indemnity payments generate costs, and thus we define these indemnity payments as costs to be considered when selling an insurance contract. However, such indemnity payments are connected with uncertainty. Considering this fact, we define $E\left(C_{1}^{0}\left(D P^{A}, x^{N}\right)\right)$ as the expected value of the indemnity payments for $t=1$ from the perspective of $t=0$ and furthermore $\xi$, which explains the expected indemnity payment difference between $t=0$ and $t=1 . \xi>0$ exhibits an unexpected increase in indemnity payments from the perspective of $t=0$ and includes the risk of error arising from forecasting and diagnostic risk (see, e.g., Kriele and Wolf 2014). ${ }^{9}$ Hence, in formal terms, we define

$$
E\left(C_{1}\left(D P^{A}, x^{N}\right)\right)=E\left(C_{1}^{0}\left(D P^{A}, x^{N}\right)\right)+\xi
$$

Based on these insights, we follow our previous definition and describe the expected cost (indemnity payment) function $E\left(c_{1}\left(D P^{A}\right)\right)$ as independent of $x^{N}$. Furthermore, we take into consideration that the default probability influences the costs. We need an estimation of the indemnity payments for $t=1$ from the perspective of $t=0$ to calculate which premium might be

\footnotetext{
${ }^{8} \mathrm{We}$ believe the simplification of a two-points-in-time model is acceptable in the case of nonlife insurance contracts since most contracts do have a yearly duration. However, at $t=1$, some of the incurred claims may not be finally settled (incurred but not reported claims IBNR and incurred but not settled claims IBNS). Hence, our used claim distribution in $t=1$ includes paid claims as well as reserved claims (taken into account with their present value in $t=1$ ). For further research according to long-term insurance business, see, e.g., Albrecher et al. (2016, 2018).

${ }^{9}$ Forecasting risk is connected with an incorrect projection of past data to forecast the future, while diagnostic risk leads to an incorrect distribution function. For instance, the distribution function of the past exhibits only an inadequate amount of data or the environment varies in a way that the distribution changes (e.g., because of extreme risk). Moreover, $\xi$ focuses on the negative deviation of the expectations (i.e., higher costs for the insurer).
} 
profitable and which not. As a result of uncertainty, the threat exists that an estimated profitable premium results in an unprofitable case.

In a next step, we introduce our option pricing framework. The values of assets $A_{t}\left(D P^{A}, x^{N}\right)$ and liabilities $L_{t}\left(D P^{A}, x^{N}\right)$ follow geometric Brownian motions. Under a real-world probability measure $P$, assets and liabilities are denoted by

$$
\begin{aligned}
d A_{t}\left(D P^{A}, x^{N}\right) & =\mu_{A} A_{t}\left(D P^{A}, x^{N}\right) d t+\sigma_{A} A_{t}\left(D P^{A}, x^{N}\right) d W_{A_{t}}^{P}, \\
d L_{t}\left(D P^{A}, x^{N}\right) & =\mu_{L} L_{t}\left(D P^{A}, x^{N}\right) d t+\sigma_{L} L_{t}\left(D P^{A}, x^{N}\right) d W_{L_{t}}^{P},
\end{aligned}
$$

where the Wiener processes are correlated with $d W_{A_{t}}^{P} d W_{L_{t}}^{P}=\rho d t . \mu_{A}$ and $\mu_{L}$ describe the drifts, while $\sigma_{A}$ and $\sigma_{L}$ determine the volatility of the stochastic processes. We further consider a risk-neutral martingale $Q$, which leads to the drifts being described by the risk-free interest rate $r$. For the sake of simplicity, we assume that under the real-world probability measure $P$, the drift is equal to the drift under $Q$ (risk-neutral market). Hence, it holds that $E^{P}(\cdot)=E^{Q}(\cdot):=E(\cdot)$. At time $t=1$, we reach the following solutions for the stochastic differential equations (see, e.g., Björk 2009):

$$
\begin{aligned}
A_{1}\left(D P^{A}, x^{N}\right) & =A_{0}\left(D P^{A}, x^{N}\right) \exp \left[r-\sigma_{A}^{2} / 2+\sigma_{A}\left(W_{A_{1}}-W_{A_{0}}\right)\right], \\
L_{1}\left(D P^{A}, x^{N}\right) & =L_{0}\left(D P^{A}, x^{N}\right) \exp \left[r-\sigma_{L}^{2} / 2+\sigma_{L}\left(W_{L_{1}}-W_{L_{0}}\right)\right],
\end{aligned}
$$

with $L_{0}\left(D P^{A}, x^{N}\right)=E\left(L_{1}\left(D P^{A}, x^{N}\right)\right) \exp (-r)$. In this article, we examine an insurer that maximizes the overall net present value between $t=0$ and $t=1$. Hence, we receive

$$
\underset{D P^{A} \in(0,1], x^{N} \in \mathbb{N}}{\arg \max } \operatorname{NPV}\left(E C_{1}\left(D P^{A}, x^{N}\right)-E C_{0}\right),
$$

where

$$
N P V\left(E C_{1}\left(D P^{A}, x^{N}\right)-E C_{0}\right)=P V\left(E C_{1}\left(D P^{A}, x^{N}\right)\right)-E C_{0} .
$$

Using the Margrabe-Fischer option-pricing formula based on two geometric Brownian motions (see Margrabe 1978; Fischer 1978), derived from Equation (13), the present value of the equity capital $E C_{1}$ is described as

$$
\begin{aligned}
P V\left(E C_{1}\left(D P^{A}, x^{N}\right)\right) & =E\left[\exp (-r) \max \left(A_{1}\left(D P^{A}, x^{N}\right)-L_{1}\left(D P^{A}, x^{N}\right), 0\right)\right] \\
& =A_{0}\left(D P^{A}, x^{N}\right) \Phi\left(d_{1}\right)-L_{0}\left(D P^{A}, x^{N}\right) \Phi\left(d_{2}\right),
\end{aligned}
$$

where

$$
d_{1}=\frac{\ln \left(\frac{A_{0}\left(D P^{A}, x^{N}\right)}{L_{0}\left(D P^{A}, x^{N}\right)}\right)+\frac{\sigma^{2}}{2}}{\sigma} ; \quad d_{2}=d_{1}-\sigma ; \quad \sigma=\sqrt{\sigma_{A}^{2}+\sigma_{L}^{2}-2 \rho \sigma_{A} \sigma_{L}} .
$$

Moreover, $\Phi$ describes the standard normal cumulative distribution function. The idea here is to analyze how different premiums influence an insurer's overall level. In this context, it is important to mention that the optimal demand for underwriting net present value maximization $N P V\left(E\left(P_{r}\left(D P^{A}, x^{N}\right)\right)\right)$ (premiums minus expected costs; see Appendix A) varies from the optimal demand for overall net present value maximization (without $\xi)^{10} N P V^{w}\left(E C_{1}\left(D P^{A}, x^{N}\right)-E C_{0}\right)$. We state in Appendix A the detailed net present value formula on the company's level and for the underwriting profit for linear as well as convex price-demand function, which we use to calculate the optimal demand numerically. Furthermore, we show in Appendix A that $E C_{0}$ induces the deviation of the net present value calculation, and, hence, the optimal demand between the overall and underwriting perspective varies. Thus, the results of a partial model are in general not optimal from the overall asset liability perspective. According to insurance practice, we derive

\footnotetext{
${ }^{10}$ The optimal demand is calculated based on the expectations for $t=1$ from the point of view of $t=0$. Since $\xi$ is only ex post known, it does not affect the optimal demands from the underwriting and overall perspective, which are determined in $t=0$, but the optimal net present values are influenced.
} 
the insight that an insurer should not maximize the underwriting net present value because of the nonoptimality. Instead, it should concentrate on overall net present value maximization to reach optimality for the insurer. As a result of this insight, we focus in the following part on the overall perspective. Taking into account that the highest net present value is reached when the default probability is minimal given the line of reasoning by using the results of Zimmer et al. (2018), we consider a variation of default probabilities in our analysis and compare between the different default probabilities how the net present value maximizing parameters of our model change. Furthermore, the convex price-demand function exhibits the following form:

$$
\pi_{\text {mean }}^{P D F, \text { con }}\left(D P^{A}, x^{N}\right)=\frac{\pi_{r}}{\eta x^{N}+1} \exp \left(-23.75 D P^{A}\right),
$$

where $\pi_{\text {mean }}^{P D F, c o n}$ is strictly monotonic decreasing for an increasing $D P^{A}$ and $\eta$ describes the slope.

\subsection{Heterogeneous Premiums}

In the presented model, we have focused on a homogeneous premium for all insurance customers. The optimal premium $\pi_{O P}^{o p t}$, which can be derived through price-demand function and expected cost function, leads to the optimal overall net present value under the condition that only one premium exists and correct expectations. However, as we have seen in Zimmer et al. (2018), the willingness to pay for a homogeneous insurance product is highly heterogeneous. This insight is supported by the understanding of imperfect information in the insurance industry (see, e.g., Rothschild and Stiglitz 1976, 1997; Holmström 1979). Based on these findings, we extend our previous model and introduce different premium levels $\pi^{\text {level }}$. As mentioned before, we consider a stepwise optimal price setting. More concretely, each additional premium level is optimal to maximize the overall net present value under correct expectations. For the one-premium case, the optimal total premium is

$$
\Pi^{\text {total }}=\pi_{O P}^{o p t}\left(D P^{A}, x_{O P}^{o p t}\right) x_{O P}^{o p t}
$$

For heterogeneous premiums, the total premium is defined as

$$
\Pi_{*}^{\text {total }}=\sum_{e=1}^{h} \Delta \Pi\left(\pi_{e}^{\text {level }}, x_{e}^{\text {level }}\right)
$$

where $\Pi_{*}^{\text {total }} \geq \Pi^{\text {total }}$ and $h$ describes the maximal premium levels. In the case of heterogeneous premiums, the demand is equal to the sum of the demand, which is generated with different premium levels. As mentioned earlier, heterogeneous premiums do not include only the chance to reach higher aggregated premiums. When the expected costs $E\left(c_{1}^{0}\left(D P^{A}\right)\right)$ are substantially lower than the expected costs $E\left(c_{1}\left(D P^{A}\right)\right)$, it can happen that the additional premium level is $>E\left(c_{1}^{0}\left(D P^{A}\right)\right)$ and $<E\left(c_{1}\left(D P^{A}\right)\right)$. Figure 3 illustrates the heterogeneous premiums (three premium levels) and the underwriting profit under correct expectations.
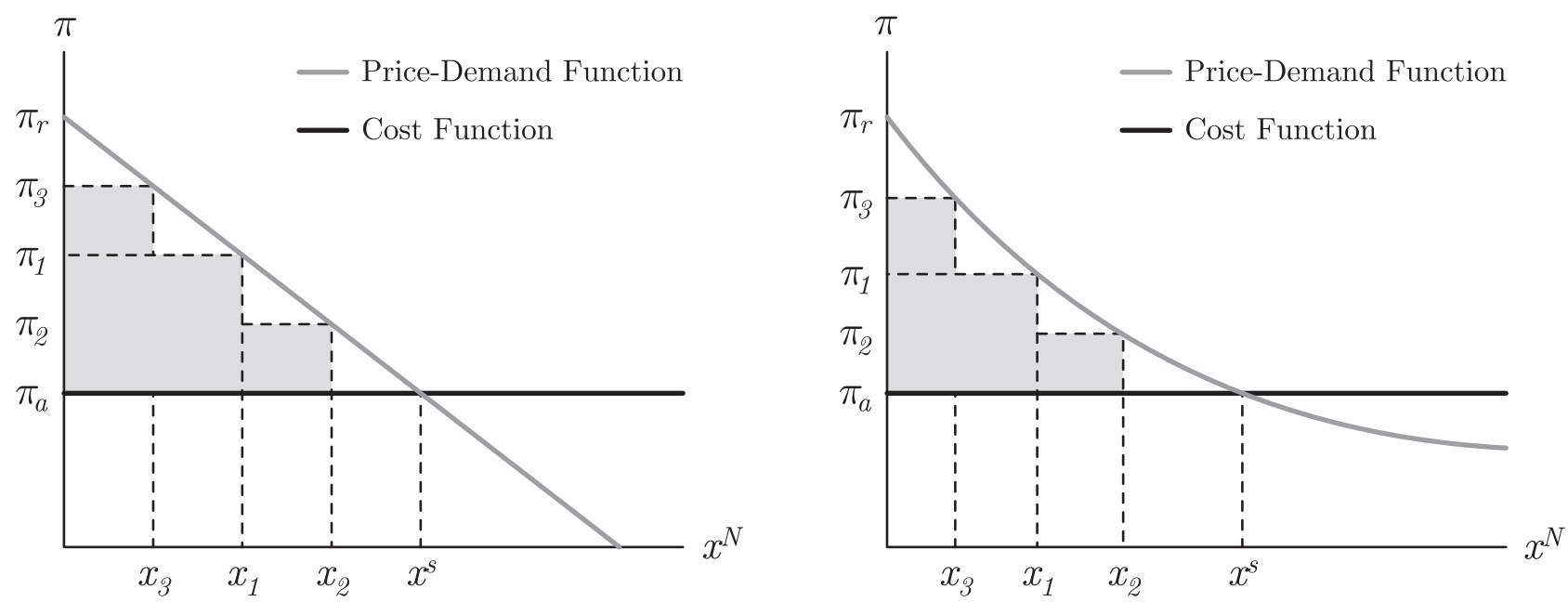

FIGURE 3. Heterogeneous Premiums under Linear and Convex Price-Demand Function. 


\subsection{Constraints}

In the next step, we define the constraints under which we consider our asset liability model. According to our first constraint, we introduce an internal solvency requirement that determines whether a certain premium level can be realized. The policyholders adapt their willingness to pay to the reported default probability $D P^{A}$. Since the actual default probability has to be smaller or equal to the reported default probability to protect policyholders and to avoid default probability discrimination, $D P^{A}$ exhibits an upper bound for the default probability. In other words, when the actual default probability is smaller or equal to the reported default probability, the solvency constraint is satisfied. Our solvency requirement is structured as

$$
P\left(A_{1}\left(D P^{A}, x^{N}\right)<L_{1}\left(D P^{A}, x^{N}\right)\right) \leq D P^{A}
$$

where

$$
\begin{gathered}
P\left(\frac{A_{0}\left(D P^{A}, x^{N}\right) \exp \left[r-\sigma_{A}^{2} / 2+\sigma_{A}\left(W_{A_{1}}-W_{A_{0}}\right)\right]}{L_{0}\left(D P^{A}, x^{N}\right) \cdot \exp \left[r-\sigma_{L}^{2} / 2+\sigma_{L}\left(W_{L_{1}}-W_{L_{0}}\right)\right]}<1\right), \\
P\left(\exp \left[\sigma_{A}\left(W_{A_{1}}-W_{A_{0}}\right)-\sigma_{L}\left(W_{L_{1}}-W_{L_{0}}\right)+\sigma_{L}^{2} / 2-\sigma_{A}^{2} / 2\right]<\frac{L_{0}\left(D P^{A}, x^{N}\right)}{A_{0}\left(D P^{A}, x^{N}\right)}\right), \\
P\left(\sigma_{A}\left(W_{A_{1}}-W_{A_{0}}\right)-\sigma_{L}\left(W_{L_{1}}-W_{L_{0}}\right)<\ln \left(\frac{L_{0}\left(D P^{A}, x^{N}\right)}{A_{0}\left(D P^{A}, x^{N}\right)}\right)-\sigma_{L}^{2} / 2+\sigma_{A}^{2} / 2\right) .
\end{gathered}
$$

With Wiener processes that follow $N(0,1)$ and uncorrelated assets and liabilities, we reach

$$
\Phi\left(\frac{\ln \left(\frac{L_{0}\left(D P^{A}, x^{N}\right)}{A_{0}\left(D P^{A}, x^{N}\right)}\right)-\sigma_{L}^{2} / 2+\sigma_{A}^{2} / 2}{\sqrt{\sigma_{A}^{2}+\sigma_{L}^{2}}}\right) \leq D P^{A} .
$$

The internal solvency constraint implies that a high asset liability ratio is needed to reach low default probabilities.

In addition, we introduce the constraint that in the homogeneous case the number of premium levels $\pi^{\text {level }}$ is equal to 1 , and in the heterogeneous case, the number of premium levels is less than or equal to 3 (see Fig. 3). We use this constraint to differentiate the heterogeneous case clearly from a continuous premium adaptation. In addition, we argue that such a continuous premium adaptation is not economically adequate for several reasons. First, heterogeneous premium levels lead to classification costs (see, e.g., Gatzert et al. 2012). Second, underlying a reputational risk is that policyholders recognize different premium levels and as a result change insurance company.

\subsection{Excursus: Remarks with Respect to a Normative Price-Demand Function}

Our previous considerations clarify for the assumed relation between default probability and willingness to pay that an insurance company strives for a default probability of 0 . In a next step, we will analyze whether for the normative pricedemand function the insurer exhibits the incentive to reach the lowest possible reported default probability if policyholders cannot replicate future cash flows and thus are paying under correct expectations more than the fair price for their insurance contract. We consider $\mu-\sigma$ preferences with risk-averse policyholders $(a>0)$. The preference function is structured as follows (see, e.g., Rymaszewski et al. 2012):

$$
\phi\left(w_{1}\right)=E\left(w_{1}\right)-\frac{a}{2} \sigma^{2}\left(w_{1}\right)
$$

where $E\left(w_{1}\right)$ denotes the expected wealth of the policyholder in $t=1$ and $\sigma^{2}\left(w_{1}\right)$ the variance of the wealth in $t=1$. Under full coverage, setting the preference function of the wealth without insurance $\phi\left(w_{1}^{N I}\right)$ equal to the preference function of the wealth with insurance $\phi\left(w_{1}^{I}\right)$, where $\phi\left(w_{1}^{I}\right):=w_{1}^{I}=w_{0}-\pi$ and $w_{1}^{N I}=w_{0}-c$, we derive the following relation for the premium $\pi$ :

$$
\pi=E(c)+\frac{a}{2} \sigma^{2}(c) .
$$


The initial wealth $w_{0}$ does not affect the premium. Induced by full coverage, $E(c)$ represents the expected indemnity payments and $\sigma^{2}(c)$ the variance of the indemnity payments. Moreover, with a rising $a$, the willingness to pay increases. The policyholder with the highest willingness to pay exhibits a risk parameter of $a_{1}$ and the policyholder with the second highest willingness to pay is described by $a_{2}$. Assuming linearity for the risk parameter, we can determine a normative price-demand function with these two points. Thus, in formal terms we reach

$$
\pi=E(c)+\frac{a_{1}}{2} \sigma^{2}(c)-\left(\frac{a_{1}}{2}-\frac{a_{2}}{2}\right) \sigma^{2}(c)\left(x^{N}-1\right) .
$$

Given the premium relation, we suppose that in dependency of the default probability the expected indemnity payments are denoted as $E\left(c\left(D P^{A}\right)\right)=E(c)\left(1-D P^{A}\right)$ and the indemnity payments variance as $\sigma^{2}\left(c\left(D P^{A}\right)\right)=\sigma^{2}\left(c \times\left(1-D P^{A}\right)\right):=$ $\sigma^{2}(c)\left(1-D P^{A}\right)^{2}$. Based on comprehensive numerical computations, we analyze how the overall net present value changes by a default probability affected normative willingness to pay under stable risk attitudes. Therefore, we examine two effects that influence the overall net present value (see Eq. [21]). The values of the standard normal cumulative distribution functions vary by the default probability since the ratio of assets and liabilities changes and assets minus liabilities are also influenced. We use $A_{0}\left(D P^{A}\right)$ and $L_{0}\left(D P^{A}\right)$ as starting points for the assets and liabilities and reach for a given demand

$$
\begin{gathered}
\frac{A_{0}\left(D P^{A}\right)}{L_{0}\left(D P^{A}\right)}=\frac{E C_{0}+x^{N}\left(E(c)\left(1-D P^{A}\right)+\frac{a_{1}}{2} \sigma^{2}(c)\left(1-D P^{A}\right)^{2}-\left(\frac{a_{1}}{2}-\frac{a_{2}}{2}\right) \sigma^{2}(c)\left(1-D P^{A}\right)^{2}\left(x^{N}-1\right)\right)}{x^{N} E(c)\left(1-D P^{A}\right)} \\
=\frac{E C_{0}}{x^{N} E(c)\left(1-D P^{A}\right)}+1+\frac{\left(\frac{a_{1}}{2}-\left(\frac{a_{1}}{2}-\frac{a_{2}}{2}\right)\left(x^{N}-1\right)\right) \sigma^{2}(c)\left(1-D P^{A}\right)^{2}}{E(c)\left(1-D P^{A}\right)} .
\end{gathered}
$$

Since

$$
\frac{E C_{0}}{x^{N} E(c)\left(1-D P^{A}\right)}>\frac{E C_{0}}{x^{N} E(c)}
$$

and

$$
\frac{\left(\frac{a_{1}}{2}-\left(\frac{a_{1}}{2}-\frac{a_{2}}{2}\right)\left(x^{N}-1\right)\right) \sigma^{2}(c)\left(1-D P^{A}\right)^{2}}{E(c)\left(1-D P^{A}\right)}<\frac{\left(\frac{a_{1}}{2}-\left(\frac{a_{1}}{2}-\frac{a_{2}}{2}\right)\left(x^{N}-1\right)\right) \sigma^{2}(c)}{E(c)},
$$

$\frac{A_{0}}{L_{0}}$ can be smaller, greater, or equal to $\frac{A_{0}\left(D P^{A}\right)}{L_{0}\left(D P^{A}\right)}$ depending on the effects. Moreover, the reservation price is reduced by $E(c) D P^{A}+\left(a_{1}-\frac{a_{2}}{2}\right)\left(\sigma^{2}(c)-\sigma^{2}(c)\left(1-D P^{A}\right)^{2}\right)$ and the expected indemnity payments decrease by $E(c) D P^{A}$, while the maximal demand, which can be sold for the intersection point between costs and price-demand function, remains constant. Thus, when we maximize the net present value, $A_{0}-L_{0}>A_{0}\left(D P^{A}\right)-L_{0}\left(D P^{A}\right)$. $\Phi\left(d_{1}\right)-\left(d_{2}\right)$ can be greater, smaller, or equal to $\Phi\left(d_{1}\left(D P^{A}\right)\right)-\Phi\left(d_{2}\left(D P^{A}\right)\right)$ depending on the available relation between assets and liabilities (see also Appendix B). For instance, if $\Phi\left(d_{1}\right)-\Phi\left(d_{2}\right)<\Phi\left(d_{1}\left(D P^{A}\right)\right)-\Phi\left(d_{2}\left(D P^{A}\right)\right)$ relatively improves the net present value under default probability $N P V\left(D P^{A}\right)$, while $A_{0}-L_{0}>A_{0}\left(D P^{A}\right)-L_{0}\left(D P^{A}\right)$ leads to a higher net present value under no default probability, $N P V$, a tradeoff between both effects results. Although we reach for all our numerical computations that $N P V>N P V\left(D P^{A}\right)$, we cannot exclude that for at least one combination $N P V\left(D P^{A}\right)>N P V$ might be possible.

\section{NUMERICAL EXAMPLES}

\subsection{Scenario under Correct Expectations}

In the following section, we provide additional insights into the model by means of different numerical examples. We vary the one-year reported default probability $(0.01,0.5,1$ percent), premium levels $(1,2,3)$, price-demand function (linear, nonlinear [convex]), and the scenario (correct expectations, cost shift). According to the default probabilities, since no default-free insurer exists in practice, we consider a reported default probability of 0.01 percent, include the maximal default probability under Solvency II (Value at Risk [VaR] confidence interval of 99.5 percent; see, e.g., EIOPA 2014), and include a higher default probability in contrast to the others. 
TABLE 2

Input Parameters for the Correct Expectation Scenario

\begin{tabular}{|c|c|c|}
\hline Default probability (\%) & $D P^{A}$ & $0.01,0.5,1$ \\
\hline Price-demand function (default case) & $\pi_{P D F}^{P D}\left(D P^{A}, x^{N}\right)$ & $\left(3000-8.5397 \times 10^{-4} x^{N}\right) \exp \left(-23.75 D P^{A}\right)$ \\
\hline Premium levels & $\pi^{\text {level }}$ & $1,2,3$ \\
\hline Equity capital & $E C_{0}$ & 1.25 billion \\
\hline Expected indemnity payments & $\pi_{a}\left(D P^{A}\right)=E\left(c_{1}^{0}\left(D P^{A}\right)\right)$ & $1000\left(1-D P^{A}\right)$ \\
\hline Correlation between Wiener processes & $\rho$ & 0 \\
\hline $\begin{array}{l}\text { Deviation between expected } \\
\text { indemnity payments over time }\end{array}$ & $\xi$ & 0 \\
\hline $\begin{array}{l}\text { Standard deviation of the stochastic } \\
\text { liability process }\end{array}$ & $\sigma_{L}$ & 0.4 \\
\hline $\begin{array}{l}\text { Standard deviation of the stochastic } \\
\text { asset process }\end{array}$ & $\sigma_{A}$ & 0.05 \\
\hline Risk-free interest rate & $\mu_{A}=\mu_{L}=r$ & 0 \\
\hline
\end{tabular}

Note: For $\pi^{\text {level }}=1, x_{*}^{N}$ and $x^{N}$ are equal. When $\pi^{\text {level }}$ is 2 or $3, x_{*}^{N}=x_{e}^{\text {level }}$, where $e$ can be 1,2 , or 3 (see Fig. 3). In contrast, $x^{N}$ is the sum of the demand which is realized with different premium levels.

\subsubsection{Input Parameters}

First, we describe a scenario with correct expectations, which means that the expected indemnity payments (from the perspective of $t=0) E\left(C_{1}^{0}\left(D P^{A}\right)\right)$, which represent the costs, do not deviate from the expected indemnity payments $E\left(C_{1}\left(D P^{A}\right)\right)$. In other words, for this scenario, $\xi=0$ and the environment is stable over time. ${ }^{11}$ According to the input parameters, we mainly refer to Eling et al. (2009) and Zimmer et al. (2018) but also include other data to enable comprehensive computations. Eling et al. (2009) consider a German nonlife insurance company which is medium-sized and focuses on automobile as well as property-casualty insurance. In the numerical example of Eling et al. (2009), the expected value of the stochastic claims after reinsurance is $€ 1.171$ billion. As we include a price-demand function in our model, we do not regard the expected claims as fixed. Instead, we assume they increase with higher demand and decrease with lower demand. Furthermore, we set the actuarially fair premium $\pi_{a}$, which is needed to compensate the expected costs of insurance, as $€ 1000$ per contract (nondefault case). Zimmer et al. (2018) show that the reservation price $\pi_{r}$ is more than a factor of 5 of the fair premium. In contrast, we calculate more defensively and take factor of 3 (€3000) as the maximum willingness to pay (nondefault case). In the case that the underlying insurance company sells the contract for the optimal premium $\pi^{o p t}$ under underwriting profit maximization, $x^{\text {opt }}=1.171$ million because the expected costs per contract are $€ 1000$. As a result of linearity in the price-demand function, $\theta$ is $8.5397 \times 10^{-4}$. Moreover, the equity capital at $t=0$ is 1.25 billion. We further consider a correlation between the Wiener processes of 0 . In addition, the standard deviation of the stochastic asset process is assumed to be 0.05 and the standard deviation of the liability process to be 0.4 . Derived from the current economic situation, the risk-free interest rate is set to 0 . Table 2 shows the input parameters.

\subsubsection{Linear Price-Demand Function}

First, we underlie a linear price-demand function, which is illustrated in Table 2. Afterward, we also consider a convex price-demand function and compare the results. Subsequently, we will focus on the solvency constraint. Under correct expectations, $\xi=0$, which means that the expected costs per demand unit never exceed the premium. We numerically determine the optimal demands for different premium levels under overall net present value maximization. Table 3 clarifies that an increase in default probability reduces the net present value substantially. For the one-premium case, between 0.01 and $1(0.5)$ percent default probability, the optimal premium decreases by 15.99 (8.36) percent. In addition, for the same relation, the net present value is even reduced by 39.68 (21.18) percent. This results from the fact that an increasing default probability decreases the willingness to pay and the demand simultaneously. Furthermore, for a scenario under correct expectations, an increase in the number of premium levels increases the net present value substantially. Moreover, it is possible to overcompensate the 0.5 percent default probability when choosing the right premium levels. For instance, comparing the one-premium and three-premium level, for $0.01(0.5 ; 1)$ percent default probability, the net present value increases by $50.13(50.22 ; 50.34)$ percent. Hence, the

\footnotetext{
${ }^{11}$ Time stability exists, which assumes that fundamental conditions of the world do not or only slightly change over time. Thus, "the past is a statistically reliable, and hence unbiased, guide to the future" (which is Davidson's definition of the objective probability environment; Davidson 1991, 130). We will show in the scenario under cost shift why such an assumption can be critical for insurance companies.
} 
TABLE 3

Linear Case: Net Present Value in Dependency of Default Probability and Premium

\begin{tabular}{lcccccc}
\hline$\pi^{\text {level }}$ & $D P^{A}($ in \%) & Premium & Demand (million) & $\Phi\left(d_{1}\right)$ & $\Phi\left(d_{2}\right)$ & $N P V\left(E C_{1}-E C_{0}\right)($ million $)$ \\
\hline 1 & 0.01 & 1994.40 & 1.172 & 0.9985 & 0.9950 & 1166.23 \\
2 & 0.01 & $1994.40,1491.76$ & $1.172,0.590$ & 0.9940 & 0.9824 & 1459.73 \\
3 & 0.01 & $2493.64,1994.40,1491.76$ & $0.586,0.586,0.590$ & 0.9962 & 0.9882 & 1750.87 \\
1 & 0.5 & 1827.63 & 1.103 & 0.9982 & 0.9939 & 919.17 \\
2 & 0.5 & $1827.63,1404.47$ & $1.103,0.558$ & 0.9923 & 0.9784 & 1151.56 \\
3 & 0.5 & $2245.86,1827.63,1404.47$ & $0.5515,0.5515,0.558$ & 0.9948 & 0.9846 & 1380.75 \\
1 & 1 & 1675.52 & 1.025 & 0.9979 & 0.9931 & 703.48 \\
2 & 1 & $1675.52,1324.66$ & $1.025,0.521$ & 0.9909 & 0.9750 & 882.13 \\
3 & 1 & $2020.65,1675.52,1324.66$ & $0.5125,0.5125,0.521$ & 0.9934 & 0.9811 & 1057.64 \\
\hline
\end{tabular}

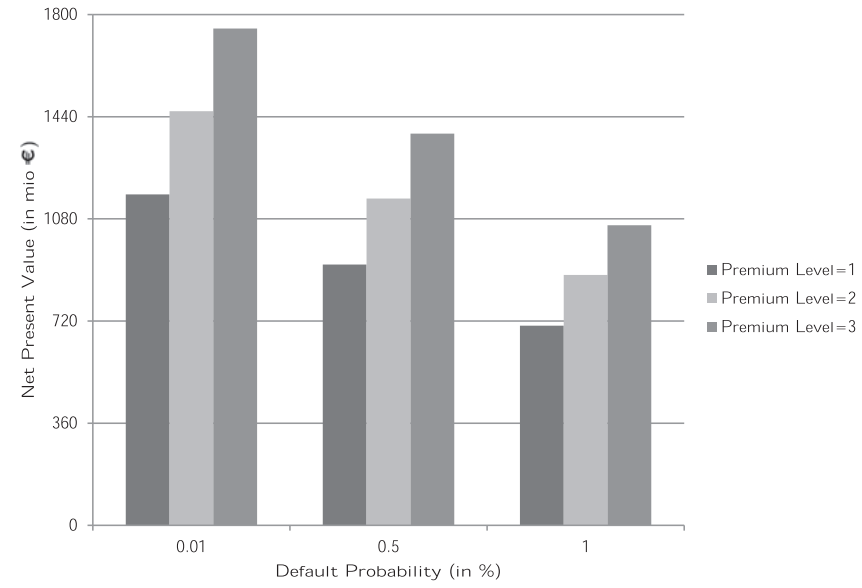

FIGURE 4. Linear PDF under Correct Expectations: NPV and Premium Levels.

results of our model are close to the theoretical considerations of Figure 2. Figure 4 shows the net present value as influenced by default probability and heterogeneous premiums.

For the examined default probabilities, the optimal demand for underwriting net present value maximization varies from optimal demand under overall net present value maximization by at most 5.37 percent. Underwriting net present value maximization refers to the relation of premiums minus expected costs (see Appendix A). An overall perspective for an insurer is necessary to sell the optimal quantity. Moreover, $\Phi\left(d_{1}\right)$ and $\Phi\left(d_{2}\right)$ decrease with a higher default probability and a lower premium adaptation $\pi^{\text {low }}$, while both increase with a higher premium adaptation $\pi^{\text {high }}$. In addition, the gap between $\Phi\left(d_{1}\right)$ and $\Phi\left(d_{2}\right)$ increases with a lower premium adaptation. Therefore, a lower premium adaptation leads to a higher net present value than a higher premium adaptation (e.g., according to 0.01 percent default probability, $€ 1491.76$ results in a higher net present value than €2493.64).

\subsubsection{Convex Price-Demand Function}

The pertinent literature often assumes a linear price-demand function (see, e.g., Einav and Finkelstein 2011; Gatzert et al. 2012). In contrast, Zimmer et al. (2018) show that a convex function describes the relation between premium and demand appropriately. Hence, in the following part we consider a convex price-demand function, which is defined in Equation (23), and compare the results with the linear case. With $\pi_{r}, \pi_{a}$, and the maximal demand (twice the optimal demand in the linear case under underwriting profit maximization), which we have determined in the previous subsection, we develop a convex price-demand function and obtain $\eta=8.5397 \times 10^{-7}$. As a result, $\pi_{r}, \pi_{a}$, and maximal demand are equal for the linear and convex price-demand function. Furthermore, as a consequence of these identical points and the convexity, $\int_{0}^{x^{S}}\left(\pi^{P D F, \text { con }}\left(x^{N}\right)-\right.$ $\left.E\left(c\left(x^{N}\right)\right)\right) d x^{N}<\int_{0}^{x^{S}}\left(\pi^{P D F, l i n}\left(x^{N}\right)-E\left(c\left(x^{N}\right)\right)\right) d x^{N}$ and $x_{c o n}^{o p t}<x_{\text {lin }}^{\text {opt }}$ as well as $\pi_{c o n}^{o p t}<\pi_{\text {lin }}^{o p t}$ (one-premium case). For three premiums, a lower and a higher premium adaptation are still optimal. 
TABLE 4

Convex Case: Net Present Value in Dependency of Default Probability and Premium

\begin{tabular}{lcccccc}
\hline$\pi^{\text {level }}$ & $D P^{A}(\%)$ & Premium & Demand (million) & $\Phi\left(d_{1}\right)$ & $\Phi\left(d_{2}\right)$ & $N P V\left(E C_{1}-E C_{0}\right)$ (million) \\
\hline 1 & 0.01 & 1727.29 & 0.858 & 0.9989 & 0.9962 & 624.46 \\
2 & 0.01 & $1727.29,1302.85$ & $0.858,0.661$ & 0.9903 & 0.9735 & 829.77 \\
3 & 0.01 & $2274.28,1727.29,1302.85$ & $0.370,0.488,0.661$ & 0.9933 & 0.9808 & 1030.52 \\
1 & 0.5 & 1626.51 & 0.747 & 0.9993 & 0.9972 & 471.96 \\
2 & 0.5 & $1626.51,1263.02$ & $0.747,0.552$ & 0.9923 & 0.9782 & 623.39 \\
3 & 0.5 & $2081.15,1626.51,1263.02$ & $0.328,0.419,0.552$ & 0.9944 & 0.9835 & 771.53 \\
1 & 1 & 1529.73 & 0.640 & 0.9996 & 0.9982 & 345.54 \\
2 & 1 & $1529.73,1224.19$ & $0.640,0.452$ & 0.9946 & 0.9840 & 453.49 \\
3 & 1 & $1902.71,1529.73,1224.19$ & $0.285,0.355,0.452$ & 0.9959 & 0.9873 & 559.28 \\
\hline
\end{tabular}

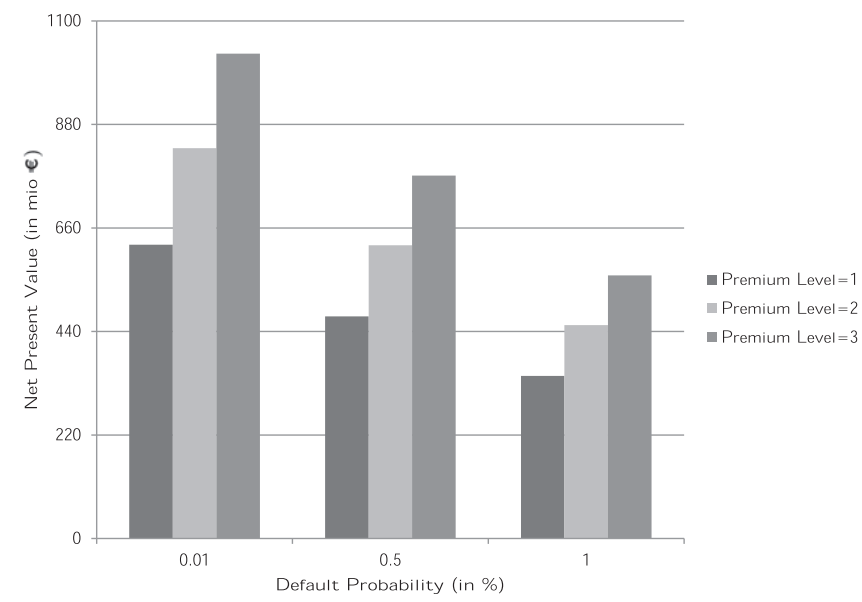

FIGURE 5. Convex PDF under Correct Expectations: NPV and Premium Levels.

Table 4 clarifies the outcome under a convex price-demand function. In contrast to the linear case, as a result of convexity, the interval between different premium levels varies substantially. For instance, the interval between optimal premium (onepremium case) and $\pi^{\text {low }}$ is much lower than the interval between an optimal premium (one-premium case) and $\pi^{\text {high }}$. Moreover, the demand of $\pi^{\text {low }}$ is higher than the demand of the other premiums (three-premium case). We will see in the next subsection that the higher quantity of $\pi^{\text {low }}$ increases the vulnerability against rising indemnity payments. Concerning the onepremium case, between 0.01 and $1(0.5)$ percent default probability, the optimal premium decreases by 11.44 (5.83) percent and the net present value by 44.67 (24.42) percent. Hence, the relative net present value reduction is even higher than in the linear case, although the relative reduction of the optimal premium is lower. Under a default probability of 0.01 percent, comparing the one-premium and three-premium levels, the net present value increases by 65.03 percent. Moreover, for 0.5 (1) percent default probability, the net present value rises by 63.47 (61.86) percent between the one-premium and three-premium levels. This is more than in the linear case. With a higher default probability, $\Phi\left(d_{1}\right)$ and $\Phi\left(d_{2}\right)$ increase since the ratio of asset and liabilities increases. In addition, considering the examined default probabilities, the optimal demand for underwriting net present value maximization differs from the optimal demand under overall net present value maximization by at most 18.75 percent. As a result of convexity, the impact of $E C_{0}$ is stronger than in the linear case. Figure 5 illustrates the development of net present value with heterogeneous premiums and default probability.

For the linear as well as the convex case, $\Phi\left(d_{1}\right)$ and $\Phi\left(d_{2}\right)$ are close to 1 as a result of the high asset liability ratio, which is necessary to fulfill the solvency constraint. For the cost shift, the difference between $\Phi\left(d_{1}\right)$ and $\Phi\left(d_{2}\right)$ increases and hence affects the net present value. 


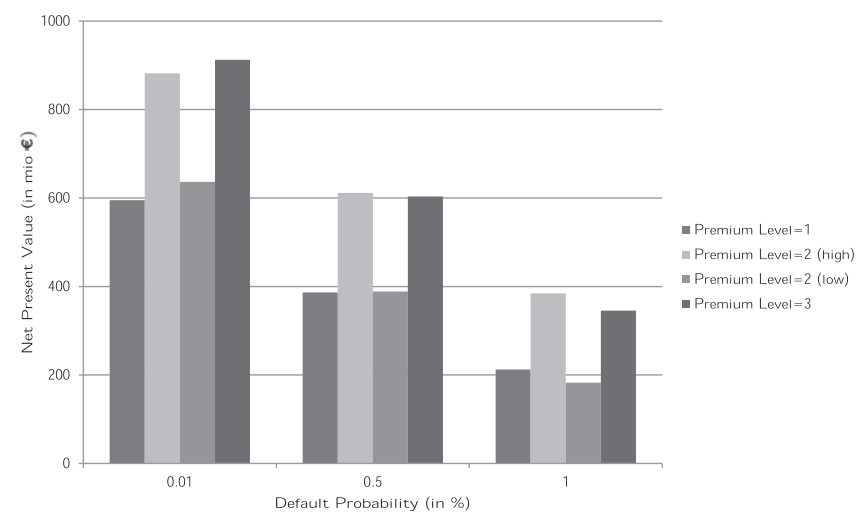

FIGURE 6. Linear PDF under Cost Shift: NPV and Premium Levels.

\subsection{Scenario under Cost Shift}

In this subsection, we will focus on a scenario under cost shift. In the scenario under correct expectations, we have described the situation as stable over time. Hence, the past can be used as guide for the future. However, our business world and its environment are changing rapidly. Therefore, the future is widely unstable. We analyze how incorrect estimations of the expected costs influence our asset liability model. Thus, we underlie a deterministic shift in the expected costs and examine the effect on the net present value of heterogeneous premiums. We assume that the deterministic shift $\xi$ increases the expected costs per demand unit by 50 percent. All other input parameters remain the same as before.

\subsubsection{Linear Price-Demand Function}

First, we analyze how the net present value is affected by the deviation of the expected indemnity payments, and afterward we take the solvency requirement into consideration. Figure 6 clarifies how the net present value is influenced by the change in the expected costs depending on the default probability and premium level. For the two-premium level, we consider both the higher and lower premium adaptation. Instead, in Figure 4, we focus on the one that results in the higher net present value. In the case under correct expectations, the net present value of the higher and lower additional premium varies only slightly. In contrast, in this case, we want to illustrate that choosing a different premium level affects the net present value substantially.

As a result of increasing expected indemnity payments, it is intuitive that each insurance contract, which is sold below such indemnity payments, is connected with a decline in net present value. However, considering this relation, at first glance it might be surprising that even a lower premium adaptation where $\pi^{\text {low }}<E\left(c_{1}\left(D P^{A}\right)\right)$ results in our analysis in a higher net present value for a default probability of $0.01(0.5)$ percent. We can explain this development with the difference between $\Phi\left(d_{1}\right)$ and $\Phi\left(d_{2}\right)$. For $\sigma>0, \Phi\left(d_{1}\right)$ is greater than $\Phi\left(d_{2}\right)$, and hence the assets are more strongly weighted than the liabilities. ${ }^{12}$ Moreover, a lower premium adaptation increases the gap between $\Phi\left(d_{1}\right)$ and $\Phi\left(d_{2}\right)$. Hence, as illustrated in Figure 6 , the increasing gap between $\Phi\left(d_{1}\right)$ and $\Phi\left(d_{2}\right)$ overcompensates $\pi^{\text {low }}<E\left(c_{1}\left(D P^{A}\right)\right)$. Nevertheless, this relation is not necessarily present. With an increasing $\sigma$ and a lower ratio of $\frac{A_{0}\left(D P^{A}, x^{N}\right)}{L_{0}\left(D P^{A}, x^{N}\right)}$, the difference between $\Phi\left(d_{1}\right)$ and $\Phi\left(d_{2}\right)$ increases and vice versa (see Appendix B). Furthermore, we recognize for a default probability of 0.5 percent, although both two-premium levels lead to a higher net present value than a homogeneous premium, three premiums are worse than the two-premium level (high). This effect is induced by the increasing asset liability ratio in comparison to the two-premium level (low). Under a $0.01(0.5,1)$ percent default probability, choosing the higher premium adaptation for the two-premium level is connected to a positive deviation in the net present value in relation to the lower premium adaptation by $245.15(222.99,202.01)$ million. In addition, the three-premium level is the best alternative for a default probability of 0.01 percent, and for 0.5 (1) percent default probability, the higher premium adaptation should be realized.

\subsubsection{Convex Price-Demand Function}

The net present value deviation under a $0.01(0.5,1)$ percent default probability between $\pi^{\text {high }}$ and $\pi^{\text {low }}$ is $264.87(226.30$, 191.50) million and decreases with a higher default probability. In addition, for a convex price-demand function, $\pi^{\text {low }}$ generates higher demand under stable conditions than higher premium levels (three-premium case). Hence, a lower premium adaptation under a convex price-demand function is riskier than under a linear price-demand function and leads to higher

\footnotetext{
${ }^{12}$ For a very low stochastic process standard deviation, $\Phi\left(d_{1}\right)$ and $\Phi\left(d_{2}\right)$ are approximately equal (see Appendix B).
} 


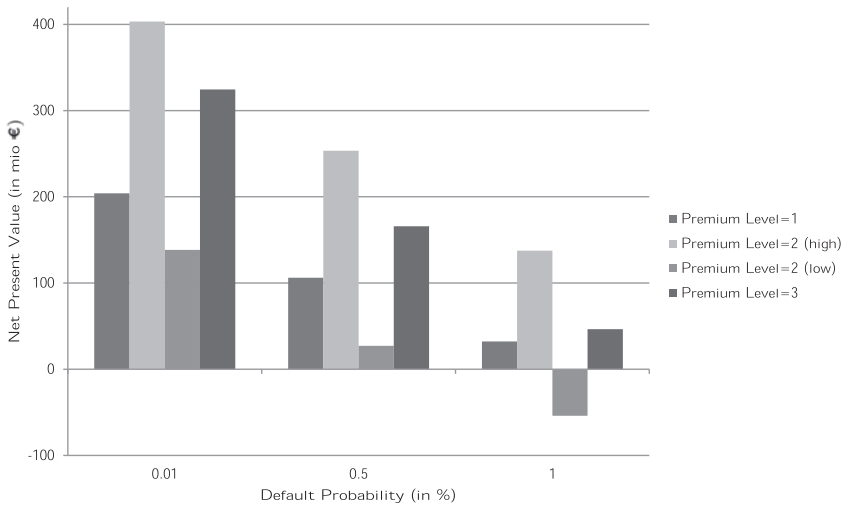

FIGURE 7. Convex PDF under Cost Shift: NPV and Premium Levels.

vulnerability against increasing expected costs. A 1 percent default probability and a lower premium adaptation yields a negative net present value. $\pi^{\text {high }}$ consequently leads to the best results under a cost shift. Figure 7 illustrates that it is possible to overcompensate a 0.5 percent default probability when choosing the right heterogeneous premiums.

In summary, the underlying example and the implications clarify that heterogeneous premiums improve the net present value when correct expectations are present and are resilient against a cost shift when choosing the right heterogeneous premiums.

The following problem is inherent for net present value maximizing insurance enterprises. In our scenario under correct expectations, an additional lower premium $\pi^{\text {low }}$ leads to a higher net present value than an additional higher premium $\pi^{\text {high }}$. Hence, if only two-premium levels are feasible, each insurer has the incentive to realize the additional lower premium. However, this premium is connected to the risk that conditions change to a scenario under cost shift, and thus a higher premium adaptation would be substantially better. When one insurance enterprise decides to ignore the potential risk of lower premiums and realizes the profit, a competitive advantage for this company would emerge as long as correct expectations are present. As a result, all other insurance companies are driven to do the same to strengthen their own market position relative to others. However, when the scenario switches from correct expectations to a cost shift and the market participants behave as described, an unfavorable outcome results. This theoretical structure of action is known as a prisoner's dilemma. ${ }^{13}$

\subsubsection{Solvency Requirement}

As we have demonstrated, a higher default probability reduces the net present value substantially under the assumptions taken in this article. However, a solvency requirement, as presented here, is useful to minimize the possibility that the actual default probability is higher than the reported default probability. In fact, solvency requirements restrict the risky behavior of an insurance company and enable an insurance enterprise to find an appropriate balance between return and risk. Thus, the customers are protected as a result of the constraints (see also Eling et al. 2007). Apart from this theoretical use of solvency requirements, we will consider in a next step whether our solvency constraint is fulfilled under correct expectations and for the cost shift. In this context, we emphasize that a deviation in the expectations of costs over time is critical for the usefulness of solvency requirements. We list the reported default probabilities and the actual default probabilities in Table 5 and Table 6. If the reported default probability $D P^{A}$ is smaller than the actual default probability in the linear (convex) case $D P^{l i n}\left(D P^{c o n}\right)$, the solvency requirement is violated.

From Table 5, we see that the solvency constraint is not fulfilled for the reported default probability of 0.01 percent under a linear as well as convex price-demand function. Moreover, several lower premium adaptations and the three-premium level also do not satisfy the constraint. Hence, the lower premium adaptation shows a higher vulnerability concerning the solvency constraint. Our solvency constraint exhibits a strong focus on the inherent threat of lower premium adaptation. For the cost shift, only under 1 percent default probability, the convex case satisfies the constraint for the higher premium adaptation (see Table 6). In all other cases, the solvency requirement is violated. A positive aspect that we derive is that solvency requirements restrict the risk to a certain degree and define a solid maximal default probability.

However, when we consider that the cost shift is not known from time $t=0$, the information that several premium-default combinations are not in line with the solvency condition does not influence the decisions of the insurer in $t=0$. The insurer's

\footnotetext{
${ }^{13}$ A prisoner's dilemma stems from the noncooperative behavior of market participants and collectively leads to an inappropriate outcome. For research on the noncooperative behavior of market participants, see, e.g., Nash (1951).
} 
TABLE 5

Correct Expectations: Reported and Actual Default Probability (\%)

\begin{tabular}{lcccccccccccc}
\hline$\pi^{\text {level }}$ & 1 & 2 (high) & 2 (low) & 3 & 1 & 2 (high) & 2 (low) & 3 & 1 & 2 (high) & 2 (low) & 3 \\
\hline$D P^{A}$ & 0.01 & 0.01 & 0.01 & 0.01 & 0.5 & 0.5 & 0.5 & 0.5 & 1 & 1 & 1 & 1 \\
$D P^{\text {lin }}$ & 0.15 & 0.08 & 0.61 & 0.39 & 0.19 & 0.11 & 0.78 & 0.53 & 0.21 & 0.13 & 0.92 & 0.67 \\
$D P^{\text {con }}$ & 0.11 & 0.06 & 0.99 & 0.68 & 0.08 & 0.05 & 0.79 & 0.57 & 0.05 & 0.03 & 0.55 & 0.42 \\
\hline
\end{tabular}

TABLE 6

Cost Shift: Reported and Actual Default Probability (\%)

\begin{tabular}{lcccccccccccc}
\hline$\pi^{\text {level }}$ & 1 & 2 (high) & 2 (low) & 3 & 1 & 2 (high) & 2 (low) & 3 & 1 & 2 (high) & 2 (low) & 3 \\
\hline$D P^{A}$ & 0.01 & 0.01 & 0.01 & 0.01 & 0.5 & 0.5 & 0.5 & 0.5 & 1 & 1 & 1 & 1 \\
$D P^{\text {lin }}$ & 2.47 & 1.54 & 6.71 & 4.89 & 2.91 & 1.95 & 7.89 & 6.06 & 3.21 & 2.30 & 8.84 & 7.11 \\
$D P^{\text {con }}$ & 1.96 & 1.25 & 9.25 & 7.19 & 1.52 & 1.05 & 7.94 & 6.38 & 1.04 & 0.76 & 6.24 & 5.18 \\
\hline
\end{tabular}

decisions are based on expectations about the costs in $t=1$ from the point of view of $t=0$. Hence, only the premium-default combinations, which are in conflict with the solvency constraint from the perspective of $t=0$, affect the insurer's behavior. This insight clarifies that an unexpected shock influences the costs of the insurance company, while the solvency constraint does not have an appropriate answer because it is based on the expectations from the perspective of $t=0$. Of course, the future is only to a certain degree predictable. Therefore, a deviation from expectations is possible and probable. Including this fact in an internal solvency framework, stress testing is an appropriate tool to analyze a miscalculation of distribution parameters.

False estimations of costs are often induced by external impacts (e.g., natural disasters (see, e.g., Lewis and Murdock 1996; Harrington 2009), political risks (see, e.g., MIGA 2014; Braun and Fischer 2018), or cyber attacks (see, e.g., Biener et al. 2015; WEF 2016)). Thus, it is important to develop an integrated approach that includes the external development, such as a market analysis, in the internal solvency considerations. Furthermore, it is necessary to develop early warning systems (see, e.g., Brockett et al. 1994) and directly implement changes of the business environment in the solvency constraints to minimize miscalculations. Moreover, forward-looking models, which anticipate future outcomes and focus on liability risk drivers, should be employed (see Swiss Re 2016). Nevertheless, solvency requirements are still a framework of action that does not guarantee the successful development of an insurance enterprise. In addition, for instance, loss reserves (see, e.g., Dus and Maurer 2003) are necessary to be able to pay the claims in $t=1$, but an increase in loss reserves over a level, defined by the solvency constraint, to compensate a potential rise in claims does not solve the problem of uncertainty and also leads to a lockup of more capital than needed under correct expectations. Instead, it is more sensible to focus on the origins of deviations between expectations over time.

In summary, we have shown in our numerical examples that the net present value decreases substantially with a higher default probability. Under correct expectations, heterogeneous premiums can compensate such a net present value reduction to a certain degree, and thus heterogeneous premiums are profitable under stable conditions. When a cost shift occurs, a higher premium adaptation still improves the net present value, where a lower premium adaptation is beneficial only when a premium greater than expected costs or $\pi^{\text {low }}<E\left(c_{1}\left(D P^{A}\right)\right)$ is overcompensated by the difference of $\Phi\left(d_{1}\right)$ and $\Phi\left(d_{2}\right)$. Solvency requirements suggest a solid maximal default probability; however, in dynamic environments, the expected costs (based on the past), which are part of the solvency constraint, may not represent the reality. Hence, the solvency requirement does not protect or only provides delays in protecting against dramatic changes.

\section{ECONOMIC IMPLICATIONS}

\subsection{Default Probability: Eminent Threat or Potential for Insurance Companies?}

As we have defined earlier, a probabilistic insurance can either be induced by the insurance company itself, which sells insurance contracts with a payoff probability lower than 1, or an inherent default probability (e.g., caused by systemic risks) results in a probabilistic insurance. Our previous analysis clarifies that the substantial decrease in policyholders' willingness to pay a premium with an increasing default probability does not provide an incentive for the insurance company to structure 
insurance contracts in a way that a payoff probability lower than 1 exists (see also Wakker et al. 1997; Zimmer et al. 2009, 2018). Therefore, insurance companies try to minimize the underlying default probability. However, in the systemic financial world, an inherent default probability is present and hence must be reported. If the policyholders are aware of such a default probability, they typically adapt their willingness to pay. As shown in our numerical examples, the potential premium, which can be generated under a default probability, is substantially lower than under nondefault. Thus, a higher default probability reduces the profit that can be achieved through insurance contracts. Hence, an increasing default probability induced, for instance, by unstable conditions under which businesses operate represents an eminent threat for insurance enterprises.

In contrast, our asset liability model also suggests that if a perceived default probability underlies, the potential also exists to improve the premiums as a consequence of the high willingness to pay for a reduction of default probability and the striving for certainty (see also Kahneman and Tversky 1979; Tversky and Kahneman 1992). Therefore, for instance, the insurance industry has the incentive to offer additional insurance contracts that pay if the first insurance contract does not pay the claims. Of course, the second insurance also exhibits an inherent default probability. Nevertheless, policyholders' striving for certainty combined with the high willingness to pay leads to the profitability of this approach.

In practice, according to the default probability, insurance contracts are highly inflexible over time. More precisely, when at $t=0$ we find an underlying reported default probability $D P^{A}$ and this default probability changes over time to $D P^{B}$, it would lead to adapting the premium to $D P^{B}$. However, this is not common in the insurance industry, although the default probability represents an important parameter of the insurance contract. In other words, policyholders gain from a decrease in default probability over time (after they have signed the contract) and are disadvantaged when the default probability increases over time (if such changes have not been rightly anticipated by the policyholders). Even if an insurance contract is not affected by a changing default probability, the behavior of policyholders might be influenced by such a variation. For instance, when the default probability increases over time, some policyholders switch insurer as a consequence of a lower willingness to pay for the underlying default probability.

\subsection{Heterogeneous Premiums: A Way to Achieve Customer Centricity}

In fact, insurance customers are heterogeneous, and heterogeneous customers consequently exhibit a heterogeneous willingness to pay even when homogeneous risks are present (see also Zimmer et al. 2018). Hence, taking into consideration that such a heterogeneity is omnipresent, for three reasons it is suboptimal for an insurance enterprise to use a homogeneous premium. First, a homogeneous premium ignores the higher willingness to pay of a bundle of customers. Thus, a gap exists between the willingness to pay and the actual acquired premium. Second, individuals with a lower willingness to pay than the homogeneous premium indicates do not have the possibility to buy an insurance contract. Third, which is derived from the two reasons above, the customer is not the focus. Instead, a decoupling between the behavior of the customer and the insurance company is present.

In contrast, heterogeneous premiums minimize the gap between higher willingness to pay and the actual acquired premium and enable individuals with a lower willingness to pay to buy the insurance, which results in higher demand and, therefore, a focus on the customer. Hence, heterogeneous premiums lead to a shift of the mind-set of an insurance enterprise. The insurance enterprise adapts the insurance premium to the willingness to pay rather than policyholders' willingness to pay to the insurance premium (which is only possible downward). As a result, customer centricity enables the insurance company to increase its profits, as measured by the net present value calculus. As we stated earlier, the customer centricity has to be within the profit restrictions under which the business operates.

According to the practicability of heterogeneous premiums in practice, this might be challenging at first glance. Given a set of different premiums for a homogeneous insurance product, we do not question that an individual who acts under bounded rationality (see Simon 1957) prefers the product with the lowest premium because each individual behaves rationally within his or her limitations. However, we see a high potential for the practicability that stems from the limitations of each individual combined with the fact that individuals accept satisfying results (see Simon 1955). In other words, it is possible for the insurer to realize premiums that are substantially higher than the fair premium. In combination with the limitation that no potential policyholder has perfect information, heterogeneous premiums are applicable. Hence, this results in a collective improvement for insurance companies through heterogeneous premiums. Furthermore, our approach clarifies that no insurance company has an incentive to maximize the transparency of the insurance market. A higher level of transparency restricts the realization of heterogeneous premiums and therefore the potential profit. However, when we take a closer look at other industries, such as the food industry, ${ }^{14}$ heterogeneous prices even work under a high degree of perceived transparency.

\footnotetext{
${ }^{14} \mathrm{We}$ refer, for instance, to a homogeneous product that is sold in the supermarket for heterogeneous prices, which is very common in our daily life.
} 
Another reason why we hold the view that heterogeneous premiums are possible to implement is the increasing relevance of digitization. Each potential policyholder has a digital footprint, and such data are useful to improve the understanding of consumer behavior and thus the willingness to pay.

\section{SUMMARY AND CONCLUSION}

In this article, we develop an asset liability model that includes the interaction of default probability, price-demand function, and insurance premiums. Therefore, we do not consider the premium as a constant factor that is ex ante given and the insurer is not a pure price taker. Instead, different strategies to generate underwriting profit, from the relation of premiums minus costs, substantially influence the overall net present value of an insurer. In this context, we introduce heterogeneous premiums in consequence of policyholders' heterogeneous willingness to pay and compare the results with the outcome under a homogeneous premium. Furthermore, we separate between higher and lower premium adaptation in regard to heterogeneous premiums. Moreover, we include an internal solvency restriction in our model. The numerical examples illustrate the net present value development under homogeneous and heterogeneous premiums with varying default probabilities when correct expectations and a cost shift are present.

Our findings include several economic implications. First, an increase in the default probability (if transparent) decreases the willingness to pay substantially and therefore restricts the potential to improve the return on capital. An inherent default probability consequently exists as a result of our systemic financial world. From the initial point that such an inherent default probability is present, policyholders' striving for certainty can be regarded as a threat but also a potential. While an increase in default probability describes the threat, taking the high willingness to pay for a default probability reduction into consideration clarifies the potential. For instance, it results in an incentive to offer additional insurance contracts that pay the claims when the first insurance contract does not.

Second, we illustrate that heterogeneous premiums are useful to improve the net present value of an insurer under a linear as well as a convex price-demand function. It is inadequate from the perspective of the insurance company for policyholders to adapt their heterogeneous willingness to pay to a homogeneous premium (which is only possible downward). Instead, adapting the premium level to the heterogeneous willingness to pay is appropriate. We further emphasize that such a heterogeneous premium adaptation is supported by limitations of the customers (e.g., missing information) and the acceptance of satisfying results. While in our scenario under correct expectations a higher and lower premium adaptation are profitable, under a cost shift a lower premium adaptation is only profitable when the premium is higher than the expected costs or the effect of a premium lower than expected costs is overcompensated by the difference in the standard normal cumulative distribution functions. A higher premium adaptation is still beneficial.

Third, we recognize that an internal solvency constraint must be structured as a forward-looking approach, which anticipates the future to identify liability risk drivers, to minimize the gap between cost expectations over time. In this context, an integrated approach is useful to combine internal and external insights. Fourth, the optimal demand under overall net present value maximization varies from the net present value maximization of an isolated premium minus costs consideration. Hence, in practice, an overall perspective should be the focus to achieve the best results from the company's point of view.

\section{ACKNOWLEDGMENTS}

The authors would like to thank Joan T. Schmit, Martin Eling, Helmut Gründl, Thomas Post, Yehuda Kahane, Sebastian Schlütter, Wai Sum Chan, two anonymous referees, the participants of the 2017 American Risk and Insurance Association (ARIA) Annual Meeting in Toronto, Canada, and the participants of the 2017 Asia-Pacific Risk and Insurance Association (APRIA) Annual Meeting in Poznań, Poland, for their valuable advice.

\section{REFERENCES}

Albrecher, H., D. Bauer, P. Embrechts, D. Filipović, P. Koch, R. Korn, S. Loisel, A. Pelsser, F. Schiller, H. Schmeiser, and J. Wagner. 2018. Asset-liability management for long-term insurance business. European Actuarial Journal 8 (1): 9-25.

Albrecher, H., P. Embrechts, D. Filipović, G. Harrison, P. Koch, S. Loisel, P. Vanini, and J. Wagner. 2016. Old-age provision: Past, present, future. European Actuarial Journal 6 (2): 287-306.

Basak, S. 2005. Asset pricing with heterogeneous beliefs. Journal of Banking and Finance 29 (11): 2849-81.

Biener, C., M. Eling, and J. Wirfs. 2015. Insurability of cyber risk: An empirical analysis. Geneva Papers on Risk and Insurance 40 (1): $131-58$.

Björk, T. 2009. Arbitrage theory in continuous time. 3rd ed. New York: Oxford University Press.

Braun, A., and M. Fischer. 2018. Determinants of the demand for political risk insurance: Evidence from an international survey. Geneva Papers on Risk and Insurance 43 (3): 397-419. 
Braun, A., H. Schmeiser, and F. Schreiber. 2017. Portfolio optimization under Solvency II: Implicit constraints imposed by the market risk standard formula. Journal of Risk and Insurance 84 (1): 177-207.

Braun, A., H. Schmeiser, and C. Siegel. 2014. The impact of private equity on a life insurer's capital charges under Solvency II and the Swiss solvency test. Journal of Risk and Insurance 81 (1): 113-58.

Brav, A., G. M. Constantinides, and C. C. Geczy. 2002. Asset pricing with heterogeneous consumers and limited participation: Empirical evidence. Journal of Political Economy 110 (4): 793-824.

Brockett, P. L., W. W. Cooper, L. L. Golden, and U. Pitaktong. 1994. A neural network method for obtaining an early warning of insurer insolvency. Journal of Risk and Insurance 61 (3): 402-24.

Brownlees, C., and R. F. Engle. 2017. SRISK: A conditional capital shortfall measure of systemic risk. Review of Financial Studies 30 (1): $48-79$.

Caginalp, G. 2005. Nonlinear price evolution. Quarterly of Applied Mathematics 63 (4): 715-20.

Cheung, K. C., W. F. Chong, and A. Lo. 2017. Budget-constrained optimal reinsurance design under coherent risk measures. Working Paper (November), Hong Kong.

Choi, J., and M. Kronlund. 2018. Reaching for yield in corporate bond mutual funds. Review of Financial Studies 31 (5): 1930-65.

Constantinides, G. M., and D. Duffie. 1996. Asset pricing with heterogeneous consumers. Journal of Political Economy 104 (2): $219-40$.

Crocker, K. J., and A. Snow. 2013. The theory of risk classification. In Handbook of insurance, ed. G. Dionne et al., 281-313. New York: Springer.

Davidson, P. 1991. Is probability theory relevant for uncertainty? A post-Keynesian perspective. Journal of Economic Perspectives 5 (1): 129-43.

Di Maggio, M., and M. Kacperczyk. 2017. The unintended consequences of the zero lower bound policy. Journal of Financial Economics 123 (1): $59-80$.

Dus, I., and R. Maurer. 2003. Integrated asset liability modelling for property casuality insurance: A portfolio theoretical approach. In Handbuch Institutionelles Asset Management, ed. H. Leser and M. Rudolf, 447-63. Wiesbaden: Gabler.

Eckert, J., and N. Gatzert. 2018. Risk- and value-based management for non-life insurers under solvency constraints. European Journal of Operational Research 266 (2): 761-74.

Einav, L., and A. Finkelstein. 2011. Selection in insurance markets: Theory and empirics in pictures. Journal of Economic Perspectives 25 (1): 115-38.

Eling, M., N. Gatzert, and H. Schmeiser. 2009. Minimum standards for investment performance: A new perspective on non-life insurer solvency. Insurance: Mathematics and Economics 45 (1): 113-22.

Eling, M., H. Schmeiser, and J. T. Schmit. 2007. The Solvency II process: Overview and critical analysis. Risk Management and Insurance Review 10 (1): 69-85.

Ellsberg, D. 1961. Risk, ambiguity, and the savage axioms. Quarterly Journal of Economics 75 (4): 643-69.

European Insurance and Occupational Pensions Authority (EIOPA). 2014. The underlying assumptions in the standard formula for the solvency capital requirement calculation. Report. Frankfurt: EIOPA.

Fischer, S. 1978. Call option pricing when the exercise price is uncertain, and the valuation of index bonds. Journal of Finance 33 (1): 169-76.

Gatzert, N., G. Schmitt-Hoermann, and H. Schmeiser. 2012. Optimal risk classification with an application to substandard annuities. North American Actuarial Journal 16 (4): 462-86.

Harrington, S. E. 2009. The financial crisis, systemic risk, and the future of insurance regulation. Journal of Risk and Insurance 76 (4): $785-819$.

Holmström, B. 1979. Moral hazard and observability. Bell Journal of Economics 10 (1): 74-91.

Kahane, Y., and D. Nye. 1975. A portfolio approach to the property-liability insurance industry. Journal of Risk and Insurance 42 (4): 579-98.

Kahneman, D., and A. Tversky. 1979. Prospect theory: An analysis of decision under risk. Econometrica 47 (2): $263-92$.

Kriele, M., and J. Wolf. 2014. Value-oriented risk management of insurance companies. London: Springer.

Lewis, C. M., and K. C. Murdock. 1996. The role of government contracts in discretionary reinsurance markets for natural disasters. Journal of Risk and Insurance 63 (4): 567-97.

Lorson, J., H. Schmeiser, and J. Wagner. 2012. Evaluation of benefits and costs of insurance regulation - A conceptual model for Solvency II. Journal of Insurance Regulation 31 (1): 125-56.

Margrabe, W. 1978. The value of an option to exchange one asset for another. Journal of Finance 33 (1): 177-86.

MIGA. 2014. World investment and political risk 2013. Washington, DC: World Bank.

Nash, J. 1951. Non-cooperative games. Annals of Mathematics 54 (2): 286-95.

Pindyck, R., and D. Rubinfeld. 2013. Microeconomics. 8th ed. New York: Pearson Prentice Hall.

Rothschild, M., and J. Stiglitz. 1976. Equilibrium in competitive insurance markets: An essay on the economics of imperfect information. Quarterly Journal of Economics 90 (4): 629-49.

Rothschild, M., and J. E. Stiglitz. 1997. Competition and insurance twenty years later. Geneva Papers on Risk and Insurance Theory 22 (2): 73-9.

Rymaszewski, P., H. Schmeiser, and J. Wagner. 2012. Under what conditions is an insurance guaranty fund beneficial for policyholders? Journal of Risk and Insurance 79 (3): 785-815.

Schlütter, S. 2014. Capital requirements or pricing constraints? An economic analysis of measures for insurance regulation. Journal of Risk Finance 15 (5): 533-54.

Simon, H. A. 1955. A behavioral model of rational choice. Quarterly Journal of Economics 69 (1): 99-118.

Simon, H. A. 1957. Models of man: Social and rational-mathematical essays on rational human behavior in a social setting. New York: Wiley.

Swiss Re. 2016. Liability risk drivers: Bringing a forward-looking perspective into liability modelling. Report. Zurich: Swiss Re.

Tan, K. S., and C. Weng. 2014. Empirical approach for optimal reinsurance design. North American Actuarial Journal 18 (2): 315-42.

Tversky, A., and D. Kahneman. 1992. Advances in prospect theory: Cumulative representation of uncertainty. Journal of Risk and Uncertainty 5 (4): 297-323.

Tversky, A., and P. Wakker. 1995. Risk attitudes and decision weights. Econometrica 63 (6): 1255-80.

Wakker, P. P., R. H. Thaler, and A. Tversky. 1997. Probabilistic insurance. Journal of Risk and Uncertainty 15 (1): 7-28.

World Economic Forum (WEF). 2016. The global risks report 2016. 11th ed. Report. Geneva: WEF.

Zimmer, A., H. Gruendl, C. D. Schade, and F. Glenzer. 2018. An incentive-compatible experiment on probabilistic insurance and implications for an insurer's solvency level. Journal of Risk and Insurance 85 (1): 245-73. 
Zimmer, A., C. Schade, and H. Gründl. 2009. Is default risk acceptable when purchasing insurance? Experimental evidence for different probability representations, reasons for default, and framings. Journal of Economic Psychology 30 (1): 11-23.

Discussions on this article can be submitted on January 1, 2020. The authors reserve the right to reply to any discussion. Please see the Instructions for Authors found online at http://www.tandfonline.com/uaaj for submission instructions.

APPENDIX A. OVERALL AND UNDERWRITING NET PRESENT VALUE

A.1. Linear Price-Demand Function

$$
\begin{aligned}
N P V^{w}\left(E C_{1}\left(D P^{A}, x^{N}\right)-E C_{0}\right) & =P V^{w}\left(E C_{1}\left(D P^{A}, x^{N}\right)\right)-E C_{0} \\
& =A_{0}\left(D P^{A}, x^{N}\right) \Phi\left(d_{1}\right)-L_{0}^{w}\left(D P^{A}, x^{N}\right) \Phi\left(d_{2}\right)-E C_{0} \\
& =\left[E C_{0}+\left(\pi_{r}-\theta x^{N}\right) \exp \left(-23.75 D P^{A}\right) x^{N}\right] \Phi\left(d_{1}\right) \\
& -\exp (-r)\left(1-D P^{A}\right) E\left(c_{1}^{0}\right) x^{N} \Phi\left(d_{2}\right)-E C_{0},
\end{aligned}
$$

where

$$
\begin{gathered}
d_{1}=\frac{\ln \left(\frac{A_{0}\left(D P^{A}, x^{N}\right)}{L_{0}^{w}\left(D P^{A}, x^{N}\right)}\right)+\frac{\sigma^{2}}{2}}{\sigma}=\frac{\ln \left(\frac{E C_{0}+\left(\pi_{r}-\theta x^{N}\right) \exp \left(-23.75 D P^{A}\right) x^{N}}{\exp (-r)\left(1-D P^{A}\right) E\left(c_{1}^{0}\right) x^{N}}\right)+\frac{\sigma^{2}}{2}}{\sigma}, \\
d_{2}=d_{1}-\sigma ; \quad \sigma=\sqrt{\sigma_{A}^{2}+\sigma_{L}^{2}-2 \rho \sigma_{A} \sigma_{L}} . \\
N P V\left(E\left(P_{r}\left(D P^{A}, x^{N}\right)\right)\right)=P V\left(E\left(P_{r}\left(D P^{A}, x^{N}\right)\right)\right) \\
=\left(\pi_{r}-\theta x^{N}\right) \exp \left(-23.75 D P^{A}\right) x^{N} \Phi\left(d_{1}\right)-\exp (-r) \pi_{a}\left(D P^{A}\right) x^{N} \Phi\left(d_{2}\right),
\end{gathered}
$$

where

$$
\pi_{a}\left(D P^{A}\right)=\left(1-D P^{A}\right) E\left(c_{1}^{0}\right) ; \quad d_{1}=\frac{\ln \left(\frac{\left(\pi_{r}-\theta x^{N}\right) \exp \left(-23.75 D P^{A}\right) x^{N}}{\exp (-r) \pi_{a}\left(D P^{A}\right) x^{N}}\right)+\frac{\sigma^{2}}{2}}{\sigma} .
$$

\section{A.2. Convex Price-Demand Function}

$$
\begin{aligned}
N P V^{w}\left(E C_{1}\left(D P^{A}, x^{N}\right)-E C_{0}\right) & =P V^{w}\left(E C_{1}\left(D P^{A}, x^{N}\right)\right)-E C_{0} \\
& =A_{0}\left(D P^{A}, x^{N}\right) \Phi\left(d_{1}\right)-L_{0}^{w}\left(D P^{A}, x^{N}\right) \Phi\left(d_{2}\right)-E C_{0} \\
& =\left[E C_{0}+\frac{\pi_{r}}{\eta x^{N}+1} \exp \left(-23.75 D P^{A}\right) x^{N}\right] \Phi\left(d_{1}\right) \\
& -\exp (-r)\left(1-D P^{A}\right) E\left(c_{1}^{0}\right) x^{N} \Phi\left(d_{2}\right)-E C_{0},
\end{aligned}
$$


where

$$
\begin{gathered}
d_{1}=\frac{\ln \left(\frac{A_{0}\left(D P^{A}, x^{N}\right)}{L_{0}^{W}\left(D P^{A}, x^{N}\right)}\right)+\frac{\sigma^{2}}{2}}{\sigma}=\frac{\ln \left(\frac{E C_{0}+\frac{\pi_{r}}{\eta x^{N}+1} \exp \left(-23.75 D P^{A}\right) x^{N}}{\exp (-r)\left(1-D P^{A}\right) E\left(c_{1}^{0}\right) x^{N}}\right)+\frac{\sigma^{2}}{2}}{\sigma} . \\
\begin{aligned}
N P V\left(E\left(P_{r}\left(D P^{A}, x^{N}\right)\right)\right) & =P V\left(E\left(P_{r}\left(D P^{A}, x^{N}\right)\right)\right) \\
& =\frac{\pi_{r}}{\eta x^{N}+1} \exp \left(-23.75 D P^{A}\right) x^{N} \Phi\left(d_{1}\right)-\exp (-r) \pi_{a}\left(D P^{A}\right) x^{N} \Phi\left(d_{2}\right),
\end{aligned}
\end{gathered}
$$

where

$$
\pi_{a}\left(D P^{A}\right)=\left(1-D P^{A}\right) E\left(c_{1}^{0}\right) ; d_{1}=\frac{\ln \left(\frac{\frac{\pi_{r}}{\eta^{N}+1} \exp \left(-23.75 D P^{A}\right) x^{N}}{\exp (-r) \pi_{a}\left(D P^{A}\right) x^{N}}\right)+\frac{\sigma^{2}}{2}}{\sigma} .
$$

APPENDIX B. STANDARD NORMAL CUMULATIVE DISTRIBUTION FUNCTIONS, ASSET LIABILITY RATIO, AND STANDARD DEVIATION OF THE STOCHASTIC PROCESSES

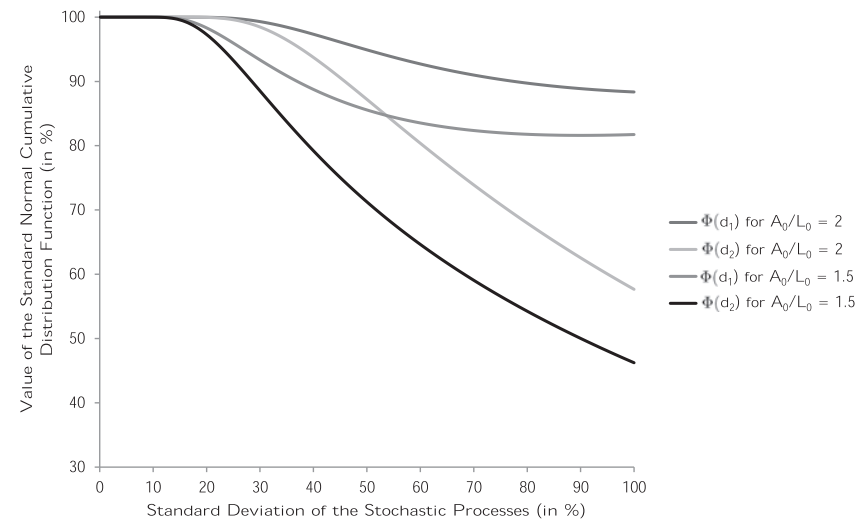

FIGURE B.1. Influence of Asset Liability Ratio and Standard Deviation of the Stochastic Processes. Note: The standard deviation of the stochastic processes refers to Equation (22). 